\title{
Chihuahua en los archivos de la Secretaría de Relaciones Exteriores
}

Carlos Illades

INSTITUTO MORA

$\mathrm{E}$

studiar la historia de un estado como Chihuahua desde el ángulo de las relaciones internacionales im. plica, cuando menos, poner atención en dos procesos relacionados entre sí: la formación del Estado nacional y la conformación de la frontera.

Chihuahua alcanzó el estatus de entidad federativa en 1824; sin embargo, su integración a la federación, en la práctica, fue un proceso largo y conflictivo. El enfrentamiento con los apaches, desde los tiempos coloniales, propició un sentimiento de independencia y una autonomía real del pueblo chihuahuense con respecto al poder central, tal como lo afirma Enrique Krauze:

La guerra reforzaba en aquellos descen- dientes de los primeros colonizadores vascos un sentido de autonomía casi medieval; exacerbación de la libertad individual (la libertad como franquía, diría Ortega y Gasset); una solidaridad y un sentimiento igualitario que nacen del enfrentamiento contra un enemigo que no discrimina, una propensión natural al autogobierno. 1

Es así que entre 1860 y 1865 el estado de Chihuahua vive fuertes conflictos con el gobierno federal, fundamentalmente por dos motivos: el destino de los bienes desamortizados del clero y el uso de los ingresos aduanales. ${ }^{2}$ En lo referente a los segundos, las autoridades chihuahuen-

${ }^{1}$ Krauze, Democracia, 1986, p. 115.

2 Ibid., p. 117. 
ses pretendian emplearlos en sufragar la guerra contra los apaches, la cual había recuperado la virulencia que tuvo en el pasado. En la presente guía (párrafo 2.1.3) se consignan materiales referidos a esta guerra.

Aunque formalmente en 1848 se estableció la frontera con Estados Unidos, fue hasta el porfiriato cuando ésta pasó de ser de indios nómadas a una real frontera con el país vecino. Al respecto, Friedrich Katz apunta:

En el último cuarto del siglo XIX, con la llegada de Díaz al poder y un flujo sin precedentes de inversiones extranjeras, principalmente norteamericanas, hacia México, la zona fronteriza del norte de México se transformó radicalmente al imponer Diaz y Estados Unidos respectivamente sus controles políticos $y$ económicos sobre la región. 3

La construcción de los ferrocarriles influyó de manera determinante en el destino del norte mexicano, en su integración al resto del país y en la esfera de influencia estadunidense. Este cambio de carácter de la frontera superpuso a los conflictos ya existentes otros de gran complejidad: migratorios, limitrofes, contrabando, defensa de la integridad territorial, penetración económica y cultural, etcétera.

Hacia 1892, bajo un cariz religioso, vuelve a entrar en crisis la relación del centro con la entidad fronteriza. Durante ese año, los tomochitecos se levantaron contra el poder federal bajo el grito de "Viva el poder de Dios y muera el mal gobierno! ¡Viva el poder de la Santísima Virgen y la Santa de

${ }^{3}$ Katz, Guerra, 1982, vol. I, p. 23.
Cabora!" ${ }^{4}$ Después de varios intentos fallidos, en 1892 el ejército federal sometió a sangre y fuego a los rebeldes chihuahuenses. En el apartado 1.4 de esta guía se da razón de algunos documentos referentes al conflicto.

La revolución de 1910 se vivió con especial intensidad en Chihuahua, afectando la relación de la entidad con el resto de México y con Estados Unidos. A diferencia de los conflictos anteriores, básicamente con el poder federal, la participación popular en 1910 tuvo en Chihuahua un móvil re. gional: enfrentar el monopolio económico y político de la mancuerna CreelTerrazas. Este hecho ayudó a formar un movimiento unificado contra los terratenientes, alcanzando la movilización popular una magnitud tal que influyó directa y decisivamente en la caída de Porfirio Díaz. Dos factores adicionales aumentaron la fuerza de los revolucionarios chihuahuenses: la proximidad con Estados Unidos y la composición social del movimiento.

La frontera con Estados Unidos permitía un fácil acceso a la compra de armamentos. La situación social (clase media) de una gran parte de las fuerzas revolucionarias hizo más fácil para éstas que para los zapatistas en Morelos o los yaquis en Sonora obtener el apoyo de la población urbana. 5

En los archivos de la Secretaría de Relaciones Exteriores (Archivo Histórico Diplomático Genaro Estrada y Archivo de Concentración) se guarda abundante información sobre el tráfi-

\footnotetext{
${ }^{4}$ Krauze, Democracia, op. cit., p. 119.

5 Katz, "Pancho", 1985, p. 91.
} 
co de armas en la frontera durante la revolución (véase parágrafo 2.2 de la presente guía) y sobre las relaciones diplomáticas con Estados Unidos durante aquellos años (véase apartado número 2).

Un incidente que tensó las relaciones diplomáticas fue la incursión de Francisco Villa en Columbus, Nuevo México, en marzo de 1916. La respuesta estadunidense ante tal agravio no se hizo esperar:

El 13 de marzo de 1916 el gobierno norteamericano envió una nota a Carranza pidiendo permiso para que una expedición punitiva norteamericana persiguiera a Villa en territorio mexicano. Aunque el presidente mexicano no concedió tal permiso, una fuerza expedicionaria al mando del general John J. Pershing cruzó la frontera el 15 de mayo y penetró al estado de Chihuahua. ${ }^{6}$

Chihuahua vivió durante varios meses la ocupación militar. En los apartados 2.1.3 y 2.4 de la guía se enl istan una serie de documentos referentes a la incursión de Villa en Columbus y el con. flicto en que derivó.

Desde el siglo XIX y, sobre todo, al concluir la fase armada de la revolución, el territorio de Chihuahua constituyó un lugar atractivo para la emigración europea y asiática, a la vez que funcionó como puente para la emigración mexicana dirigida hacia Estados Unidos. En casi todos los párrafos del 2 al 15 de la guía, se incorpora un apar-

${ }^{6} \mathrm{Katz}$, Guerra, op. cit., vol. I, p. 351. Para dos valoraciones distintas del acontecimiento véase vol. I, pp. 346-354 y Krauze, Entre, 1987, pp. 91-95. tado referente a los asuntos migratorios.

Otro problema acompañado de abundantes testimonios documentales es el diferendo sobre El Chamizal. El Tratado de Guadalupe-Hidalgo (1848) estableció los límites territoriales mexicano-estadunidenses (véanse los apartados 2.1.4 y 2.1.10) quedando el río Bravo, desde el valle de El Paso hasta el Golfo de México, como línea divisoria entre los dos países. En 1864 el río desplazó su curso hacia el lado mexicano, dejando a El Chamizal dentro del territorio del país vecino. A los dos años del fenómeno fluvial, la cancillería mexicana presentó una reclamación exigiendo la reubicación de la línea fronteriza. Estados Unidos hizo oídos sordos a la solicitud mexicana y no fue sino hasta 1910 cuando se discutió de nueva cuenta el problema limítrofe, recurriéndose al arbitraje internacional. No obstante que el laudo favoreció a México, el gobierno estadunidense no lo acató.

Durante varias décadas continuó el problema fronterizo y, en 1963, los presidentes de México y Estados Unidos emitieron un comunicado conjunto sobre la situación de El Chamizal. Finalmente, el 28 de octubre de 1967 fue devuelto a México el territorio en litigio. ${ }^{7}$

La guía que presentamos a continuación se elaboró con base en la documentación clasificada que se encuentra en el Archivo Histórico Diplomático Genaro Estrada y el Archivo de Concentración de la Secretaría de Relaciones Ex.

7 Para lo referente a El Chamizal véase, en especial, el párrafo 2.1.10 de la presente guía. 
teriores. Dicha documentación abarca el periodo 1826-1983. El material reunido contiene temáticas muy variadas: informes políticos y económicos, visitas, invasiones, incursiones, negociaciones sobre límites, sublevaciones fronterizas, conflictos políticos, elecciones, tratados, convenios, correspondencia, informes comerciales, contrabando, servicios consulares, protección, migración, justicia, etcétera.

La clasificación del material obedece a cuatro criterios básicos: geográfi$c o$, fuente informativa, tema general y asunto específico. En lo referente al criterio geográfico se enlistan, después de Chihuahua, los países americanos, europeos y asiáticos que tienen que ver con la entidad. La siguiente instancia de clasificación es la fuente informativa: legación, embajada, consulado o cancillería. Cuando ignoramos el nombre de la oficina que generó la información, incluimos la ficha dentro del rubro "generalidades".

De acuerdo con el criterio temático, la documentación se incorpora a varios apartados: asuntos políticos, actividades consulares, asuntos económicos, actividades diplomáticas, etcétera. Finalmente, con base en el asunto específico abordado en los documentos, éstos se clasifican en los apartados: comercial, sanitario, protección, etcétera.

Los cuatro criterios están organiza. dos jerárquicamente, enlistándose en primer término la información general y, por último, la más precisa y específica. Para mayor claridad, antes de la guía reproducimos el modelo de clasificación utilizado. Se respetó la redac. ción original de las fichas que hay en los archivos.

\section{Chinuahua/México}

1. Generalidades.

1.1 Límites. Noticias, reseñas e informes.

1.2 Actividades diplomáticas.

1.2.1 Asuntos administrativos.

1.2.2 Franquicias.

1.2.3 Reclamaciones.

1.2.4 Asilo político.

1.2.5 Extradición.

1.2.6 Noticias, reseñas e informes.

1.3 Asuntos políticos.

1.3.1 Política exterior.

1.3.2 Política interior.

1.3.2.1 Documentos, estudios y correspondencia.

1.3.2.2 Gobierno.

1.3.2.3 Justicia.

1.3.2.4 Poder legislativo.

1.3.2.5 Conflictos políticos.

1.3.2.6 Asuntos administrativos.

1.3.2.7 Noticias, reseñas $e$ informes.

\subsection{Asuntos militares.}

1.5 Asuntos económicos.

1.5.1 Minería.

1.5.2 Ganaderia.

1.5.3 Comercio.

1.5.4 Contrabando.

1.5.5 Transportes.

1.6 Actividades consulares.

1.6.1 Asuntos administrativos.

1.6.2 Servicios consulares.

1.6.3 Registro civil.

1.6.4 Migración.

1.6.5 Nacionalidad.

1.6.6 Protección.

1.6.7 Desastres.

1.6.8 Funciones auxiliares de justicia. 
1.6.9 Funciones auxiliares de las demás dependencias del ejecutivo.

1.6.10 Actividades comerciales y culturales.

1.7 Cancillería de México.

1.7.1 Instrucciones.

1.7.2 Asuntos políticos. Documentos, estudios y correspondencia.

2. Chihuahua/México y sus relaciones con Estados Unidos.

2.1 Límites.

2.1.1 Documentos, estudios y correspondencia.

2.1.2 Planos, mapas y croquis.

2.1.3 Fugitivos, invasiones e incursiones.

2.1.4 Informes sobre linderos, fijación de la línea fronteriza y monumentación.

2.1.5 Negociaciones.

2.1.6 Reclamaciones.

2.1.7 Representantes.

2.1.8 Obras de infraestructura.

2.1.9 Comisión de Límites.

2.1.10 Acuerdos, convenciones, convenios y tratados.

2.2 Actividades diplomáticas.

2.2.1 Visitas.

2.2.2 Reclamaciones.

2.2.3 Acuerdos, convenciones, convenios y tratados.

2.3 Asuntos políticos.

2.3.1 Política exterior.

2.3.2 Noticias, reseñas e informes.

2.4 Asuntos militares.

2.5 Asuntos económicos.

2.6 Actividades consulares.

2.6.1 Migración.

2.6.2 Justicia.

2.6.3 Protección.

2.6.4 Funciones auxiliares de las demás dependencias del ejecutivo.
2.7 Legación de México en Estados Unidos.

2.7.1 Actividades diplomáticas.

2.7.1.1 Correspondencia.

2.7.1.2 Negociaciones.

2.8 Consulados de México en Estados Unidos.

2.8.1 Límites.

2.8.1.1 Problemas fronterizos.

2.8.1.2 Obras de infraestructura.

2.8.2 Actividades diplomáticas. Reclamaciones.

2.8.3 Asuntos políticos.

2.8.3.1 Política interior.

2.8.3.2 Noticias, reseñas e informes.

2.8.4 Asuntos militares. Noticias, reseñas e informes.

2.8.5 Asuntos económicos. Noticias, reseñas e informes.

2.8.6 Actividades consulares.

2.8.6.1 Asuntos administrativos.

2.8.6.2 Sanidad.

2.8.6.3 Protección.

2.8.6.4 Funciones auxiliấtes de justicia.

2.8.6.5 Actividades comerciales y culturales.

2.8.6.6 Noticias, reseñas e informes.

2.9 Embajada de México en Estados Unidos. Actividades consulares. Actividades comerciales y culturales.

2.10 Consulados de Estados Unidos en Chihuahua. Actividades consulares.

2.10.1 Representantes.

2.10.2 Asuntos administrativos.

2.10.3 Protección.

2.10.4 Actividades comerciales y culturales.

2.10.5 Noticias, reseñas e informes.

2.11 Embajada de Estados Unidos en México.

2.11.1 Actividades diplomáticas.

2.11.1.1 Asuntos administrativos. 


\section{Bicte Satfart: \\ Farbaftige Siftoriett.

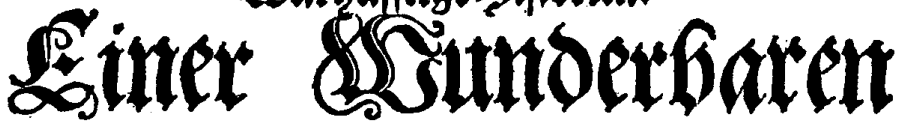

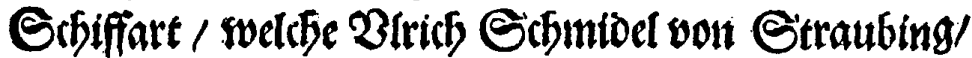
bon Lnsso 2.53 4. bif Anno I 554 , in Americam ober Deatwerwe(t) bey Brafilia vno Rio della Plata getḩan. VWas er in biefen Reanketfeen

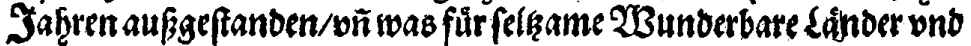

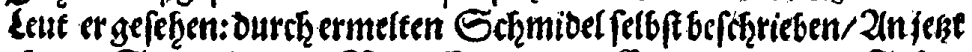
aber, an Zag geben mit $\mathfrak{Z}$ erbeferung ono Corrigierung der Státf/

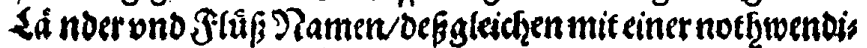
gen Landaffel/ Figuren/onbanderer methe

Erflerung/gejieret/ Durth

LEVINVM HVLSIVM. EDITIO SECVNDA.

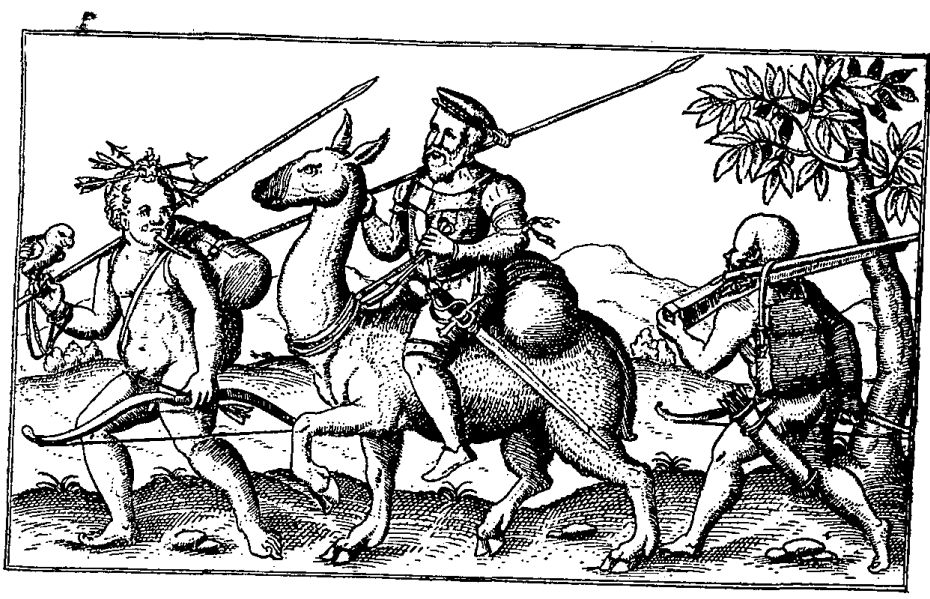

$N O R I B E R G A$. Impenfis Levini Hulfij $A N N_{N} O \quad 1602$. 
2.11.1.2 Franquicias.

2.11.1.3 Reclamaciones.

2.11.2 Asuntos políticos. Noticias, reseñas e informes.

2.11.3 Actividades consulares. Protección.

2.12 Cancillería de Estados Unidos.

2.12.1 Actividades diplomáticas.

2.12.1.1 Correspondencia.

2.12.1.2 Reclamaciones.

2.12.1.3 Negociaciones.

2.12.2 Asuntos militares. Noticias, reseñas e informes.

2.12.3 Actividades consulares. Protección.

3. Chihuahua y sus relaciones con Bolivia. Consulados de Bolivia en Chihuahua. Actividades consulares. Representantes.

4. Chihuahua/México y sus relaciones con Canadá. Migración. Actividades consulares.

5. Chihuahua/México y sus relaciones con Costa Rica. Consulados de Costa Rica en Chihuahua. Actividades consulares. Representantes.

6. Chihuahua/México y sus relaciones con Costa Rica. Consulados de Costa Rica en Chihuahua. Actividades consulares. Representantes.

7. Chihuahua/México y sus relaciones con Alemania.

7.1 Actividades consulares. Protección.

7.2 Legación de Alemania en México. Actividades consulares. Protección.

7.3 Consulados de Alemania en Chihuahua. Actividades consulares. Representantes.
8. Chihuahua/México y sus relaciones con España.

8.1 Actividades diplomáticas. Asilo político.

8.2 Actividades consulares. Protección.

8.3 Consulados de España en Chihuahua. Actividades consulares.

8.3.1 Representantes.

8.3.2 Migración.

8.3.3 Noticias, reseñas e informes.

9. Chihuahua/México y sus relaciones con Francia.

9.1 Actividades consulares. Protección.

9.2 Consulados de Francia en Chihuahua. Actividades consulares. Repre. sentantes.

10. Chihuahua/México y sus relaciones con Italia. Consulados de Italia en Chihuahua. Actividades consulares. Representantes.

11. Chihuahua/México y sus relaciones con Italia. Consulados de Italia en Chihuahua. Actividades consulares. Representantes.

12. Chihuahua/México y sus relaciones con Suiza. Consulados de Suiza en $\mathrm{Chi}$ huahua. Actividades diplomáticas. Reclamaciones.

13. Chihuahua/México y sus relaciones con la URSS. Embajada de la URSS en México. Actividades consulares. Protección.

14. Chihuahua/México y sus relaciones con China.

14.1 Actividades consulares. 
14.1.1 Migración.

14.1.2 Protección.

14.2 Legación de China en México. Actividades consulares. Protección.

15. Chihuahua/México y sus relaciones con Japón.

15.1 Actividades consulares. Migración.

15.2 Consulados de México en Japón. Actividades consulares. Migración.

GUÍ A DOCUMENTAL Chihuahua/MÉxico

1. Generalidades.

1.1 Límites. Noticias, reseñas e informes.

1883. Publicaciones referentes a planes de anexión de Chihuahua a Estados Unidos de América. III/210 (73:72)/1 II-2-34

1.2 Actividades diplomáticas.

1.2.1 Asuntos administrativos.

1966. Entrada y salida de diplomáticos extranjeros del estado de Chihuahua. III/553 (721.4)1 III-2829-4

1.2.2 Franquicias.

1929. La señora Esperanza Porras, vecina de la ciudad de Chihuahua, solicita a la SRE la exención de derechos en juguetes comprados en Estados Unidos para los niños pobres de dicha localidad. IV-55-10
1.2.3 Reclamaciones.

1916. Creación de la Comisión Unida Mexicano-A mericana para tratar de resolver las reclamaciones surgidas por la invasión del territorio americano por el general Francisco Villa. uI/250 (72:73)/ 17-11.185 (dos partes)

1.2.4 Asilo político.

1914. Refugiados civiles y militares [en] El Paso, Texas. LE. 772 (1)

1.2.5 Extradición. .

1913. Solicitud de extradición de Francisco Villa.

$$
\text { /230(02)/ }
$$$$
\text { 9-9.49 }
$$

1916. Solicitud del gobierno de Texas al de Chihuahua para la extradición de Francisco Cano y Manuel Zapata. 16-17-9

1.2.3 Noticias, reseñas e informes.

1965. Circular a embajadas de Centroamérica y Sudamérica relacionada con [el] incidente militar en Madera, Chihuahua, entre miembros del ejército y [un] grupo civil armado. IIIT-3004-2

1.3 Asuntos políticos.

1.3.1 Política exterior.

1910. Vecinos de Parras de la Fuente, Coahuila, solicitan que esta Secretaría haga las gestiones necesarias para recobrar Bahía de Magdalena, para que los niños mexicanos puedan concurrir a las escuelas americanas y para que sea reconocido El Chamizal como propiedad de la nación.

15-26-18

1912. Dificultades del gobierno de Chihuahua con el cónsul alemán en [la localidad]. 16-7.128

\subsubsection{Política interior.}


1.3.2.1 Documentos, estudios y correspondencia.

1847. Correspondencia con el gobierno de Chihuahua relativa a la guerra con Estados Unidos.

1.11.1143

1920. Carta de Miguel Diaz Lombardo para Francisco Villa, relativa al movimiento rebelde contra el gobierno. 17-17-415

1920. Carta de Antonio I. Villarreal sobre movimientos de Francisco Villa.

17-17-347

\subsubsection{Gobierno.}

1846. Consulta el gobernador de Chihuahua sobre planes de defensa y medidas que deben tomarse contra los extranjeros sospechosos que se introduzcan en el estado, dada la guerra que existe con Estados Unidos.

$$
\text { 1.11.1148 }
$$

1847. Las autoridades de Chihuahua y $\mathrm{Oa}$. xaca juran la Constitución de 1824, reformada en 1847.

5-16-84-10.

1862. Circular comunicando que Benito Juárez establece su gobierno en Chihuahua, esperando que los mexicanos lucharán hasta rechazar a los franceses invasores.

5-15-8435

1865. El cónsul en Franklin acusa recibo de la circular sobre traslado de gobierno [federal] a Chihuahua, durante la intervención francesa. 3.15-5370

1910. Gobernador de Chihuahua. L-E-619

1910. José María Sánchez, gobernador [de] Chihuahua.

$$
\text { L-E-613 }
$$

LE-615

1910-1911. Gobernador de Chihuahua. L-E-622, 624, 662 (4)

1911. F. Portillo, jefe político de Ciudad Juárez, Chihuahua. L.E-624, 625
1911. Jefe político de Chihuahua. L-E-626

1911. Chihuahua. Situación política. L-E-635

1911. Abraham González, gobernador provisional del estado de Chihuahua.

LE-626

1911. Alberto Terrazas, gobernador del estado de Chihuahua. L-E-626

1913. Chihuahua. Situación política. L-E-766 (2)

1913. Situación [en] Chihuahua. L-3-781 (3)

1913. Cambio de poderes [en] Chihuahua, Chihuahua. 6-13.85

1913. Luis Terrazas solicita permiso de importación de pertrechos al consulado de México en El Paso, Texas, para la defensa de sus intereses. 28-9-120

1914. Francisco Villa se declara gobernador [de] Chihuahua. L-E-789 (15)

1914-16. Gobernador de Chihuahua. L-E-811 (1)

1923. Manifiesto del presidente municipal de Ojinaga, Chihuahua. L-E-870 (3)

1.3.2.3 Justicia.

1848. El norteamericano Benito Lenton desaloja de sus casas y terrenos a vecinos de Chihuahua. 6-17.51

1894. Víctor L. Ochoa, cómplice en el asalto a la aduana de Palomas (tres partes).

9.5-16

9.5-17

9.5-18

1896. Palomas. Abigeato y bandolerismo. 15.7-26

1905-06. Francisco Villa y otro, su prisión por riña.

17-25-510 
1907. Sentencia a revoltosos [en] Chihuahua.

\section{L-E-1244}

1911. Atentado [en] Ciudad Juárez, Chihuahua.

$$
\text { L-E-648 (1) }
$$

1911. Atentado [en] Ciudad Juárez, Chihuahua.

$$
\text { L-E-648 (1) }
$$

1913. Robo a una fábrica de whisky por soldados en Ojinaga. 16-9-252

1919. Pide el ministro se procure el castigo a Francisco Villa por el asesinato de Alberto Bassaneti [ocurrido] en 1916.

$$
\text { 16-28-99 }
$$

1922. Juzgado de Primera Instancia de Chinipas, Chihuahua, informa sobre las actuaciones y causas criminales.

9-18-352
1922. Chihuahua. Los juzgados informan de las causas criminales de extranjeros tramitadas durante el año.

9-18-327

1922. Causas criminales tramitadas durante el año [por los] juzgados de Chihuahua.

$$
\text { 9-19-151 }
$$

1923. Causas criminales tramitadas durante el año [por los] juzgados de Chihuahua. 9-19-152

1924. Causas criminales tramitadas durante el año [por los] juzgados de Chihuahua.

$$
\text { 9-19-153 }
$$

1925. Causas criminales tramitadas durante el año [por los] juzgados de Chihuahua.

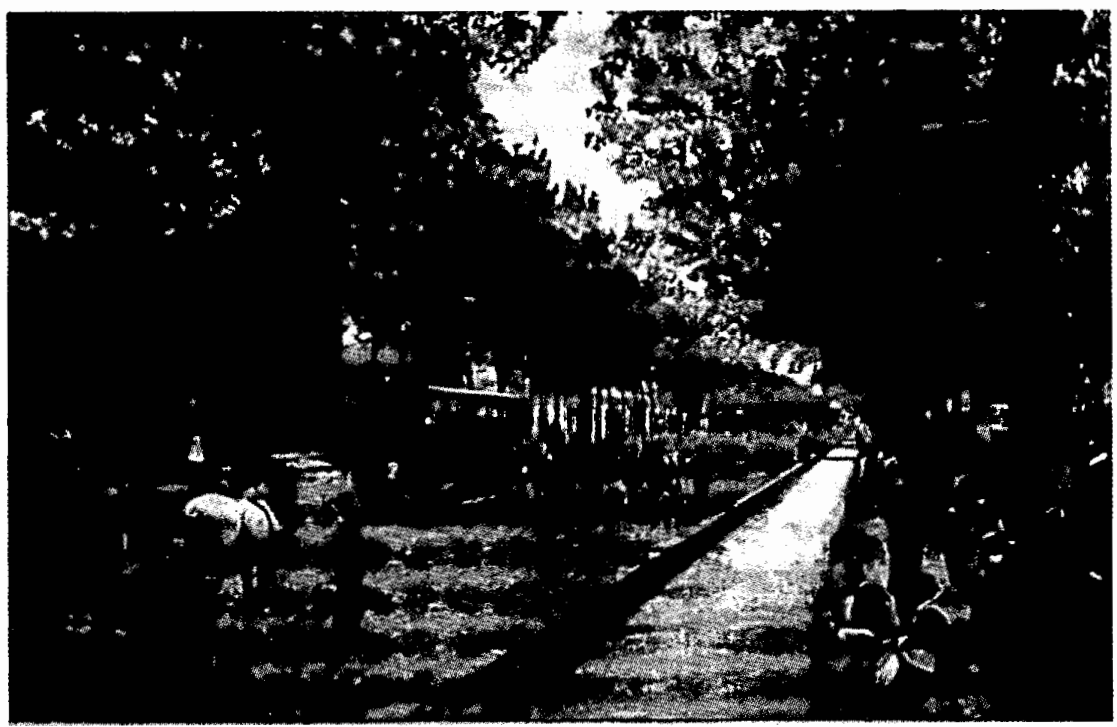


1.3.2.4 Poder Legislativo.

1822-1844. Elección de diputados y sustitutos [Parral]. 2.3-2249

1882-1887. Exposición de los representantes de Chihuahua en el Congreso de la Unión (Eduardo Urueta y Fernández, R. Guerrero y M. León) sobre las últimas depredaciones cometidas por los indios bárbaros procedentes de las reservaciones americanas y gestiones de Matías Romero (ministro de México en Estados Unidos) ante el citado gobierno. 132. ff. 20-23-61

\subsubsection{Conf lictos políticos.}

1880-1882. Movimiento revolucionario [en] Chihuahua: L-E-726 (1) (3)

1890-1899. María Teresa Urrea, Santa de Cabora. Su participación en el movimiento armado en los estados de Chihuahua y Sonora. $124 \mathrm{ff}$. 11-19-11

1896. Movimiento revolucionario de Teresa Urrea (Santa de Cabora) en Chihuahua. L-E-730 (1)

1908. Conspiración revolucionaria [en] Casas Grandes, Chihuahua. L.E-821

1910. Agitación en Parral, Chihuahua. LE-616

1910. Captura de rehenes [en] Chihuahua.

L.E-622

1910. Disturbios en Ciudad Juárez, Chihuahua. L.E-630

1910-1911. Movimientos revolucionarios en Sonora y Chihuahua. L.E-690

1911. Movimientos revolucionarios en Chihuahua, Coahuila y Sonora. L.E-623 (1)

625

633 (1)
1911. Chihuahua. Conspiración contra el gobernador por magonistas. L-E-851 (2)

1911. Revoltosos en Ojinaga, Chihuahua. L-E-647

1911. Rebelión en Ciudad Juárez, Chihuahua. LE-622

1912. Rebelión en Chihuahua. L.E-742 (3)

1912. Rebelión [en] Chihuahua. L-E-743 (3)

1912. Manifiesto de Pascual Orozco. L-E-746 (6)

1914. Manifiesto del general Francisco Villa contra Venustiano Carranza. L-E-788 (22)

1915. Señor Venustiano Carranza, primer jefe del Ejército Constitucionalista, se niega a establecer embargo contra Francisco Villa. 17-10-283

1916. Manifiesto de Francisco Villa. L-E-801-(18)

1916. Pacto [de] Ciudad Juárez. L-E-727 (3)

1916. Rebelión [en] Chihuahua. L-E-842 (5)

1917. Ocupación de los edificios en Palomas. 17.7.292

1924. Se acusa de recibo la información del cónsul de México en El Paso, Texas, relacionada con los movimientos de Adolfo de la Huerta (2 de julio). A-825 (minutas 601 a 700)

1930. Intervención del cónsul mexicano [en] El Paso, Texas, señor Medina Barrón, en asuntos políticos del estado de Chihuahua (3 de septiembre).

$$
\text { A-1495 }
$$

1942. Consulta de la Confederación Nacional Ganadera (regional Chihuahua) sobre si es debida o no la intromisión del cónsul americano en 
Ciudad Juárez, al solicitar varios informes relacionados con contribu. ciones, prácticas agrarias, etcétera. III-628.20

1.3.2.6 Asuntos administrativos.

1916-17. El gobierno de Chihuahua remite lista de los extranjeros norteamericanos residentes en dicho estado. 44-1-23

1923. Gobierno del estado [solicita] permiso para importar cartuchos. 37-19-173

1923. Alfonso Bravo Herrera, poseedor de mascarillas de Francisco Villa y Miguel Trujillo, las ofrece en venta al gobierno.

37-19.21

1924. Se acusa de recibo la información del cónsul de México en El Paso, Texas, relacionada con los movimientos de Adolfo de la Huerta ( 2 de julio). A-825 (minutas 601 a 700)

1930. Dirección Forestal y de Caza y Pesca consulta [al] consulado sobre prohibición de caza mayor y menor en el estado de Chihuahua. IV-245-5

1930. Se piden datos al gobernador del estado para conseguir [el] fomento del turismo. IV-168-5

1930. Gobierno del estado [solicita] permiso para importar armas. IV-214.32

1933. [Chihuahua] Sobre proyecto de colonización del señor Gustavo M. Salazar en el rancho "Las Virgenes". III-138-2

1933. Gestiones del señor Valentín Vázquez, en representación de la Federación de Sindicatos Obreros del Norte para que el puente internacional de Ciudad Juárez permanezca abierto toda la noche. in-140-36

1934. Informes sobre personal y funcio- narios que integran [el gobierno] del estado de Chihuahua. 1.7-24

1934. Gobierno de Chihuahua. Su solicitud de las formas demográficas. $1-12-27$

1.3.2.7 Noticias, reseñas e informes.

1911. Informes de los sucesos causados por los revolucionarios en Chihuahua. L-E-625

1913. Ciudad Camargo, Chihuahua. Informes políticos. L-E-773 (8)

1919. Recortes de prensa relativos al manifiesto de Francisco Villa y cargos hechos al presidente Carranza y $\mathbf{P a}$ blo González. 11-3.126

1923. Informes y datos sobre el asesinato de Francisco Villa en Parral, Chihuahua.

$$
27.4 .57
$$

1937. La Secretaría de Hacienda informa de actividades de grupos contrarios al gobierno en Ciudad Juárez, Chihuahua (18 de febrero).

$$
\text { A-104-13 }
$$

1950. Informes de prensa relativos a que se descubrió una estación radiodifusora clandestina en Chihuahua, que operaba bajo las órdenes del refugiado español Enrique Ricard. III-2076-16

1.4 Asuntos militares.

1880-1882. Movimiento revolucionario en Chihuahua.

$$
\text { L-E-726 (1) (31) }
$$

1890-1899. María Teresa Urrea "Santa de Cabora". Su participación en el movimiento armado de los estados de Chihuahua y Sonora durante los citados años. $124 \mathrm{ff}$. 11-19-11

1896. Movimiento revolucionario de María Teresa Urrea "Santa de Cabora" 
en Chihuahua.

L-E-730 (1)

1906. Ataque a Jiménez, Chihuahua. LE-854 (5), $855(1,2)$

1908. Disturbios por revolucionarios en Chihuahua. LE-724 (2)

1910. Maderistas rebeldes; encuentros militares en Chihuahua, Guerrero, Hidalgo y Puebla. L-E-614

1910. Insurrección en Chihuahua. L-E-618

1910. Levantamiento de rebeldes en Chihuahua, Chihuahua. L.E-619

1910. Informes sobre levantamientos revolucionarios en Chihuahua, Chihuahua. L-E-61 1

1910. Enfrentamiento entre rebeldes y tropas federales [en] Cerro Prieto, Chihuahua.

$$
\text { L-E-712 (2) }
$$

1910. Insurrección [en] Cerro Prieto, Chihuahua.

$$
\text { L.E-617, } 618 \text { y } 619
$$

1910. Ataque de revolucionarios [a] Casas Grandes, Chihuahua. LE-622

1910. Ataque [a] Chihuahua. L-E-623 (2)

1910. Ciudad Juárez, Chihuahua. Ataque por revolucionarios. L-E-622, 623 (1), 648

$$
\text { (1) }
$$

1910. Chihuahua. Movimientos revolucionarios.

$$
\text { LEE-613 }
$$

1910. Ataque por revolucionarios [a] Galeana.

$$
\text { L-E-622 }
$$

1910-11. Ciudad Juárez, Chihuahua. Toma por revolucionarios.

1911. Movimiento revolucionario en Chihuahua, Coahuila y Sonora. L.E-623 (1) 625

\section{$633(1)$}

1911. Maderistas; enfrentamiento militar con las fuerzas federales y revolucionarias en Santa Bárbara, Chihuahua. L-E-670

1911. Ciudad Juárez, Chihuahua. Armisticio. LE-687 (1)

1911. Tropas federales contra rebeldes en Ciudad Juárez, Chihuahua. L-E-611 (1)

1911. Rebeldes atacan Chihuahua. L.E-835 (3)

1911. Enfrentamiento entre federales y revolucionarios maderistas [en] Santa Bárbara, Chihuahua. LE- 670

1911. Juzgado de Instrucción militar. Causa en contra de los rebeldes [en] Chihuahua. L-E-645 (2)

1911. Derrota maderista [en] Casas Grandes, Chihuahua.

$$
\text { LE-640 }
$$

1911. Fuerzas rurales de Ciudad Juárez a Nogales. LE.682 (3)

1911. Arroyo del Cobre, Chihuahua. Encuentro entre federales $e$ insurgentes.

$$
\text { LE- } 647
$$

1911. Camargo y Jiménez, distritos desprovistos de fuerzas federales. LE-622

1911. Revolucionarios en Chihuahua y Guerrero.

$$
\text { LE-633 (1) }
$$

1911. Paso de fuerzas rurales de Ciudad Juárez, Chihuahua a Nogales. L-E-682 (3)

1911. Levantamiento de revolucionarios [en] Ciudad Juárez, Chihuahua. L-E-637 (2)

1911. Refuerzos para Ojinaga, Chihuahua.

$$
\text { L-E-622, } 648 \text { (2) }
$$

1911. Revuelta en Chihuahua y Sonora. L.E-648 (1) 
1911. Revolucionarios en Chihuahua.

$$
\text { L.E-639 }
$$

1911. Ciudad Guerrero ocupada por fuerzas federales.

$$
\text { L-E-625 }
$$

1911. Ataque [a] Ciudad Juárez, Chihuahua. L-E-646

1911. Ataque a Ciudad Juárez, Chihuahua por rebeldes. L.E-688 (12)

1911. Ataque revolucionario [a] Ciudad Juárez, Chihuahua. L.E-665

1911. Batalla [en] Ciudad Juárez, Chihua. hua.

$$
\text { L-E-685 (3), } 686 \text { (10) }
$$

1911. Batalla en Ciudad Juárez, Chihuahua.

$$
\text { L-E-835 (3) }
$$

1911. Enfrentamiento entre fuerzas militares y rebeldes [en] Ciudad Juárez, Chihuahua.

$$
\text { L-E-661 (1) }
$$

1911. Entrada del coronel Rábago a Ciudad Juárez, Chihuahua.

$$
\text { L.E-63் }
$$

1911. Rurales para mejor vigilancia en Ciudad Juárez, Chihuahua.

1911. Ataque [a] Chihuahua y Ciudad Juárez, por Enrique Flores Magón y seguidores.

$$
\text { L-E-623 (1) }
$$

1911. Chihuahua. Ataque por revoltosos. L-E-639 (2)

1911. Revolucionarios rumbo a Santa Rosalia, Chihuahua.

$$
\text { L.E-622 }
$$

1911. Ciudad Juárez, Chihuahua. Toma por los revolucionarios.

$$
\text { L-E-633 (1) }
$$

1911. Tiroteo cerca de Ciudad Juárez, Chihuahua.

$$
\text { L-E-685 (1) }
$$

1911. Fuerzas federales en Chihuahua.

$$
\text { L E-685 (1) }
$$

1911. Proyecto de ataque [a] Casas Grandes, Chihuahua.

$$
\text { L-E-817 }
$$

1911. Fuerzas federales. Enfrentamiento militar con revolucionarios maderistas en Santa Bárbara, Chihuahua. L.E- 670

1911. Fuerzas federales en Chihuahua. L.E-624

1911. Destrucción de líneas férreas y telegráficas [en] Ciudad Juárez, Chihuahua. L-E-647

1911. Levantamiento de revolucionarios [en] Chihuahua. L.E.637 (2)

1912. Movimiento orozquista. L-E-736 (1), 742,757 (6), 759 (8), 825

1912. Transporte y envio [de] armas y municiones a Manuel Lauda, jefe de armas en Ojinaga, Chihuahua. L-E-772 (7)

1912. Evaluación de Ciudad Juárez porfuerzas revolucionarias orozquistas. L-E-745 (1)

1912. Fuerzas ex revolucionarias; motín en Ciudad Juárez, Chihuahua.

$$
\text { L.E-745 (9) }
$$

1912. Ataque de Pascual Orozco hijo [a] Ojinaga, Chihuahua.

$$
\text { L-E-744 (3) }
$$

1912. Rebeldes de Batopilas.

$$
\text { LE-747 (2) }
$$

1912. Movimiento orozquista [en] Ciudad Juárez, Chihuahua.

$$
\text { L-E-831 (2) }
$$

1912. Derrota y persecución de rebeldes en Cuchillo Parado.

$$
\text { L-E-744 (3) }
$$

1912. Levantamiento [en] Ciudad Juárez, Chihuahua. L-E-817

1912. Guarnición (de] Ciudad Juárez. L-E-740 (1)

1912. Rendición de Ojinaga, Chihuahua. L-E-746

1912. Revoltosos en Ojinaga, Chihuahua. L.E-646

1912. Movimiento de rebeldes en Ojina- 
ga, Chihuahua.

L-E-744 (3)

1912. Solicitud del gobernador de Sonora al presidente de México para que se gestione, ante el gobiemo de Estados Unidos de América, la autorización para la importación de armas para la defensa del estado y para ayudar a las fuerzas militares del gobiemo, que combaten a las fuerzas rebeldes que se encuentran en los estados de Sonora y Chihuahua.

L-E-828

1912. Batalla [en] Ciudad Juárez, Chihuahua.

L-E-680

1912. Evacuación por fuerzas revolucionarias orozquistas [Chihuahua]. L-E-745 (1)

1912. Recuperación de la plaza de Ciudad Juárez.

L-E-745 (1)

1912. Llegada del coronel José de la Cruz Sánchez [a] Cuchillo Parado. L-E-744 (3)

1912. Toma [de] Ciudad Juárez. L-E-755 (10)

1912. Levantamientos [en] Chihuahua. L-E-740 (1)

1912. Autorización para embarque [de armas] rumbo a Chihuahua. L-E-848 (2)

1913. Movimientos para establecer el orden en Chihuahua. L-E-716 (2)

1913. Derrota de rebeldes en Chihuahua. L-E-714 (5), 715 (3)

1913. Armas y municiones para los rebeldes en Ojinaga, Chihuahua. L.E-773 (1)

1913. Movimientos rebeldes en Chihuahua.

L-E-780 (2)

1913. Revolucionarios [en] Santa Rosalia, Chihuahua. L.E-767 (10)

1913. Juan $\mathrm{N}$. Vázquez, jefe de armas de Ciudad Juárez.
L-E-714 (6), 715 (1)

1913. Jefe de armas de Ciudad Juárez.

L.E-716 (1)

1913. Movimientos para establecer el orden en Chihuahua. LE-716(2)

1913. Toma [de] Jiménez, Chihuahua. LE-764 (2)

1913. Toma [de] Ojinaga, Chihuahua. LE-757 (9) (5)

1913. Rebeldes [en] Ojinaga, Chihuahua. L.E. 773 (1) (5)

1913. José de la Cruz Sánchez, jefe rural en Ojinaga, Chihuahua. L-E-767 (7)

1913. Rebeldes en Ciudad Camargo, Chihuahua.

$$
\text { L.E-762 (18) }
$$

1913. Ataque [a] Ciudad Juárez, Chihuahua.

$$
\text { L-E-749 (10) }
$$

1913. Evacuación [de] Ciudad Juárez, Chihuahua.

$$
\text { L-E-780 (2) }
$$

1913. Ocupación por Francisco Villa [de] Ciudad Juárez, Chihuahua. L-E-864 (4)

1913. Depredaciones de rebeldes en Chihuahua. L-E-777 (18)

1913. Ciudad Juárez, Chihuahua. Toma por los revolucionarios villistas. L.E-778 (1)

1913. Toma [de] Ciudad Juárez por el revolucionario Francisco Villa.

$$
\text { LE-715 (3) }
$$

1913. Toma [de] Ciudad Juárez.

$$
\text { L-E-806 (1) }
$$

1913. Toma de la aduana [de] Ciudad Juárez, Chihuahua.

$$
\text { L-E-832 (2) }
$$

1914. Ocupación del ferrocarril de Parral a Durango. . 16-13:254

1914. Huertistas invaden Chihuahua. L-E-797 (14)

1914. Batalla [en] Ciudad Juárez, Chihuahua. 
L-E-781 (4)

1914. Cañones y ametralladoras para los villistas de Ciudad Juárez, Chihuahua (periódico, f. 3). LE-793 (1)

1914. Evacuación de la plaza de Ojinaga. L-E.784 (2)

1914. Evacuación de la Plaza de Ojinaga. L.E-797 (19)

1914. Fusilamiento de carrancistas en Ciudad Juárez, Chihuahua. L.E-789 (15)

1914. Fuerzas rebeldes en Camargo, Chihuahua. L-E-784 (2)

1914. Filibusteros huertistas; derrota en Ciudad Juárez, Chihuahua L-E-796 (7)

1915. Chihuahua. Ataque por rebeldes. L-E-835 (3)

1915. Rendición de jefes revolucionarios de Chihuahua. LE-808 (8)

1915. Movimiento revolucionario villista en Ciudad Juárez, Chihuahua. L-E-810 (1)

1915. Movimiento villista. Derrota por constitucionalistas. L-E-868A

1916. Derrota de Francisco Villa por el general Murguía. 17-6.190

1916. Ataque de Francisco Villa [a] Casas Grandes, Chihuahua. L-E-800 (1)

1916. Toma por fuerzas villistas [de] $\mathrm{Pa}$ rral, Chihuahua. L-E-806

1916. Asalto [a] Chihuahua por rebeldes villistas. L-E-798 (4)

1916. Asalto de villistas [a] Chihuahua. L-E-806 (2)

1916. Caída de Chihuahua. LE-727 (3)

1916. Ataque de villistas [a] Ciudad Juárez, Chihuahua. L-E-800 (2)
1916. Chihuahua. Movimientos villistas. L-E-725

1916. Ataque villista [a la] plaza de Chihuahua. LE-729 (8)

1916. Persecución de villistas en Galeana, Chihuahua. LE-800 (1)

1916. Manuel Pérez Romero remite recortes de periódicos relativos a la derro. ta de Villa en Chihuahua. 17.9-109

1916-1918. Movimiento villista en la frontera norte de México. L-E-802 (11), 721, 722, 723, 724 (7), 725

1916, 1917, 1919. Movimiento revolucionario villista en Cananea, Sonora; Ojinaga, Chihuahua, y Saltillo, Coahuila.

$$
\begin{aligned}
& \text { L-E-838 (2, 3, 4) } \\
& 724 \text { (7) }
\end{aligned}
$$

1917. Movimiento felicista en Chihuahua. LE-838 (4)

1917. Movimiento de tropas [en] Casas Grandes, Chihuahua. LE-802 (7)

1917. Movimiento armado [en] Ciudad Camargo, Chihuahua.

$$
\text { L-E-803 (11) }
$$

1917. Derrota de villistas [en] Jiménez, Chihuahua.

$$
\text { L-E-803 (12) }
$$

1917-19. Movimiento revolucionario villista en Ciudad Juárez, Chihuahua. LE-838

1917. Ataque de villistas a Ojinaga, Chihuahua. LE-799 (9)

1917. Movimiento armado en Ciudad Camargo, Chihuahua. LE-803 (11)

1917. Toma por villistas [de] Ojinaga, Chihuahua. L.E-803 (2)

1917. Movimiento de tropas en Casas Grandes, Chihuahua. L-E-802 (7) 


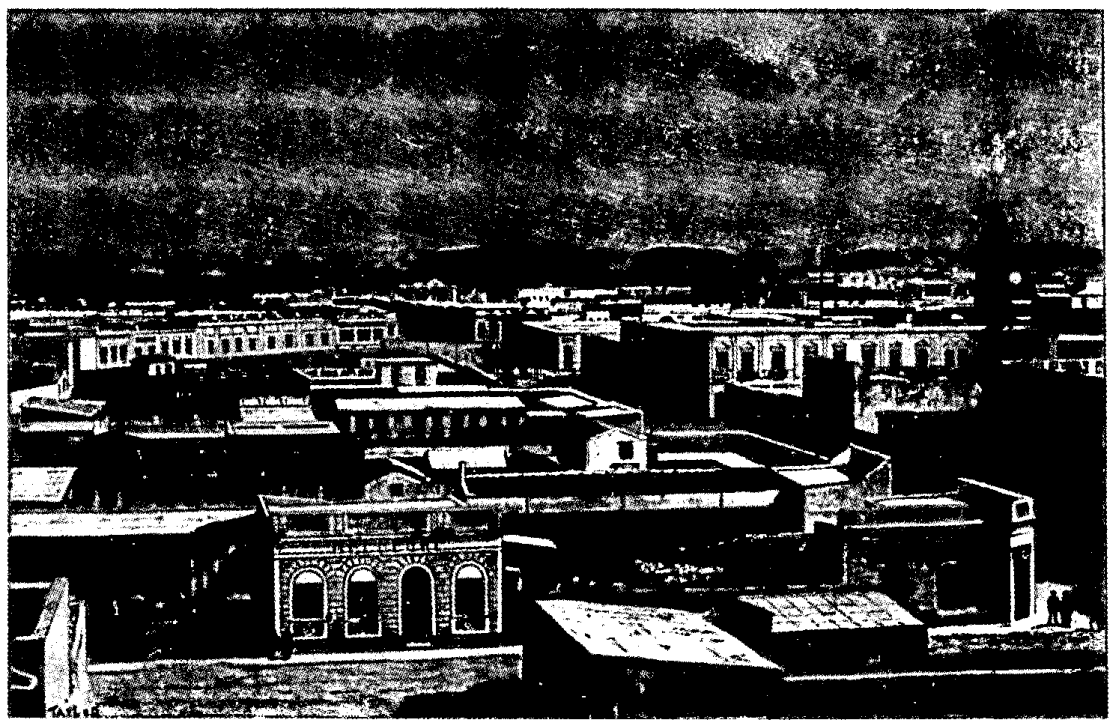

1917. Encuentro militar de villistas con tropas del gobierno de México en la frontera norte. L-E-802 (7)

1919. Movimiento revolucionario en Chihuahua, Chihuahua. LE-838 (4)

1919. Francisco Villa herido por Ángel Calderón. 17-16-186

1920. Fuerzas armadas contra los villistas en San Juan, Chihuahua. L-E-858 (3)

1923. Francisco Villa [pide] permiso para importar diez mil cartuchos. 37.19-199

1926-1927. Manifiesto al ejército revolucionario de Chihuahua.

L-E-853 (2)

1929. Fabricación [de] armas en Ávalos, Chihuahua. L-E-696 (5)
1929. Bombardeos por rebeldes escobaristas en Bermejillo, Chihuahua. L.E-696 (6)

1929. Fabricación [de] armas en Chihuahua.

$$
\text { L-E-815 (15) }
$$

1929. Movimiento villista (elementos que no se han amnistiado).

$$
\text { L-E-863 (12) }
$$

1948: Solicitud hecha por el comandante del 4o. ejército de Estados Unidos para que se autorice el paso de policía militar norteamericana a Ciudad Juárez, Chihuahua, a fin de dar servicio de patrulla én ocasión del paso de tropas norteamericanas estacionadas en Fort Bliss y Tez., en calidad de turistas.

$$
\text { III-2057-6 }
$$

1965. Circular a embajadas de Centroamérica y Sudamérica relacionada con [el] incidente militar en Made- 
ra, Chihuahua entre miembros del ejército y [un] grupo civil armado. III-3004-2

\subsection{Asuntos económicos.}

\subsubsection{Minería.}

1890. Alex R. Shepard. Administrador de las minas de Batopilas.

$$
\text { 15.3-101 }
$$

1911. La embajada de Estados Unidos pide protección para las minas: Minas Prietas, Creston Comanche Co. y la Duramill Co., en Sonora; Dolores Mines Co. y El Rayo Mines Co., en Chihuahua.

16-4.96

1915. La Compañía Minera de Batopilas se queja de haber pagado tres veces un tercio de sus contribuciones. 16-15-235

1918. La embajada de Estados Unidos pide protección para las compañías mineras en Chihuahua. 16.25.63

1920. John Johnston [pide] permiso para adquirir fundos mineros para la Chinipas Cold, S.A. 201-PB-28

1926. Cámara Nacional de Minería [Chihuahua] consulta sobre interpretación de la Ley Orgánica. 293-PB-33

1926. El señor Charles Gabrielson solicita permiso para adquiririr fundos $\mathrm{mi}$ neros para la sociedad Santa Bárbara Mining and Milling Company S.A.

306-PB-21

1926. Maurice Minchen y otros solicitan permiso para constituir la Santa Bárbara Mining Company. 260-PB-68

1928. Compañía Chihuahua Esperanza Cold Mining. Permisos para adquirir bienes.

$$
\text { 310-PB- } 47
$$

1929. [La] Cámara Nacional de Ganadería
[Chihuahua] hace consulta sobre permiso para adquirir bienes. 20-30-5

1929. Cámara Nacional de Minería [Chihuahua] consulta sobre adquisición de bienes por extranjeros. 77-PB-63

1929. Fausto E. Miranda y otros solicitan permiso para constituir [la] sociedad denominada Galeana Mining Company, S.A. 65-PB-52

1929. Informes remitidos por la Cámara Nacional de Minería [Chihuahua]. IV-290-10

1931. El consulado en Fresno pide informes sobre el denuncio de minas en Chihuahua. IV/194/30

1931. Gobierno.del estado de Chihuahua pide informes sobre [el] mercado de berilio, topacio y turmalino. Iv-509-21

1933. John Oscar Hauge y otros solicitan permiso para constituir la Chihuahua Consolidated and Milling Company. 330-PB-50

1933. José Rodríguez Moncada y socio solicitan permiso para constituir la Chihuahua Consolidated Mining Company. 330-PB-1

1934. Rodolfo J. García y Gustavo de la Garza solicitan permiso para reformar la escritura de la Compañía Minera La Camarguense, S.A.

124-PB-17

1947. [La] Batopilas Mining Company solicita buenos oficios para que se recaben informes de las autoridades correspondientes, acerca de los impuestos que adeuda.

III-10-16-26

\subsubsection{Ganadería.}

1929. Cámara de Ganadería del estado de Chihuahua hace consulta sobre permiso para adquirir bienes. 
$20-30 \cdot 5$

\subsubsection{Comercio.}

1913. Compra de armas [en] El Paso, Texas. L.E-761 (14)

1923. [La] Cámara de Comercio de Chihuahua, Chihuahua solicita lista de compradores de mineral de zinc.

37-18-145

1929. Exportación de dinamita a Ciudad Juárez, Chihuahua. L.E-696 (1)

\subsubsection{Contrabando.}

1911. Contrabando de armas [por] El Paso, Texas. L-E-688 $(1,5,12)$

1914. Contrabando de armas en Ciudad Juárez, Chihuahua. L-E-797 (13)

1916. Contrabando [de] armas para los villistas. L.E-803 (18)

1917. El consulado de México en Presidio, Texas informa de contrabando de animales de "Tinajón" o de "La Mancha".

28.9.116

1918. Plata que el bandolero Villa pretendió pasar clandestinamente a Ojinaga. 17.5.21

1919. Recortes de prensa en los que [se informa que] Francisco Villa pasó a Estados Unidos barras de plata, en cambio de pertrechos de guerra.

$11 \cdot 3 \cdot 125$

1920. Informes sobre el contrabando de armas y parque para los villistas. 17-17-342

1926. Contrabando de abarrotes [en] Ojinaga, Chihuahua. L-E-858 (3)

1928. Contrabando de armas [por] El Paso, Texas. L-E-710

1929. Contrabando de armas para los escobaristas en Ciudad Juárez, Chi- huahua.

$$
\text { L-E-696 (6) }
$$

1936. Contrabando de parque por Ciudad Juárez, Chihuahua ( 27 de octubre). A.104.12

1947. Contrabando de pieles secas por la frontera de El Paso, Texas. III-1606-12

1.5.5 Transportes.

1916. Confiscación de materiales para la reparación del ferrocarril de Parral a Durango.

16-16-105

1923. Ferrocarriles. Restablecimiento del tráfico entre Aguascalientes, Zacatecas y Ciudad Juárez. L-E-840 (9)

1.6. Actividades consulares.

1.6.1 Asuntos administrativos.

1923. La Cámara de Comercio de Chihua. hua pide informes sobre si tiene[n] aplicación en la industria las conchas de colores.

37-19-129

1927. [La] Cámara Nacional de Comercio [Ciudad Juárez] solicita informes sobre permiso de bienes. 337-PB-18

1929. Solicita al consulado de New Orleans folletos de los que remitió la Escuela Preparatoria de Agricultura de Ciudad Juárez. Iv-264-43

1931. El consulado en Fresno pide informes sobre el denuncio de minas en Chihuahua. IV $/ 194 / 30$

\subsubsection{Servicios consulares.}

1917. Exhumación de cadáveres de varios americanos para ser trasladados a Estados Unidos. 16-20-121

1918. Pasaportes expedidos por el gobierno del estado [de] Chihuahua, [durante] enero, febrero, marzo y 
abril.

38-3-60

1920. Pasaportes expedidos por el gobierno del estado [de] Chihuahua, [de] enero a diciembre.

38-3-59

1921. Pasaportes expedidos por el gobierno del estado [de] Chihuahua, [durante] los meses de enero a noviembre.

38-3-36

\subsubsection{Registro civil.}

1933. [Chihuahua]. Sobre gestiones del licenciado Federico Sodi para obtener divorcios en el extranjero e instrucciones de esta secretaría [SRE] impidiendo tan indebido proceder. III-124-7

\subsubsection{Migración.}

1912. Colonia de mormones [en] Chihua. hua.

$$
\text { LE-728 (7) }
$$

1912. Colonia [de] mormones. Chihuahua.

$$
\text { LE-741 (9) }
$$

1.6.5 Nacionalidad.

1881. Varios vecinos de Guadalupe, Chihuahua solicitan se les rehabilite en sus derechos de ciudadanos mexicanos.

43-4.66

1.6.6. Protección.

186688. El gobernador del estado de Chihuahua envía a la Secretaría de Relaciones Exteriores informes sobre los norteamericanos presos en Chihuahua.

20-23-78

1916. Ataque a colonias mormonas [en] Casas Grandes, [Chihuahua]. L-E-796 (1)

1922. Chihuahua. Los juzgados informan de las causas criminales de extranjeros tramitadas durante el año.

\section{9-18-327}

1.6.7 Desastres.

1932. Informes sobre incendio del puente internacional entre Ojinaga y Presidio.

IV-1816

1941. [La] Legislatura de Chihuahua comunica [sobre] conflagración en los archivos de su edificio. I-25.22

1.6.8 Funciones auxiliares de justicia.

1929. El señor Fernando Roldán se queja contra la aduana de Ciudad Juárez por cobro de derechos de importación en objetos de uso personal. IV-226-47

1.6.9 Funciones auxiliares de las demás dependencias del ejecutivo.

1911. Clausura de la oficina de correos de Ciuđad Juárez, Chihuahua. L-E-685 (3)

1911. Nombre de los empleados de la aduana [de] Ciudad Juárez, Chihuahua. L-E-686 (30)

1912. Casa de Moneda de Chihuahua. LE-727 (1)

1912. Aduana de Camargo. LE-733 (17)

1920. Aduana fronteriza de Ciudad Juárez, Chihuahua. Remesas de fondos al consulado de El Paso. 21-8-84

1922. Pasaportes expedidos por la Inspección de Migración [de] Chihuahua, Chihuahua [durante] el mes de ene. ro. $36 \cdot 17-44$

1923-30. Listas [de] terrenos nacionales que se conocen en la Secretaría de Agricultura y Fomento, ubicados en los estados de: [Chihuahua], Coahuila, Sinaloa, Sonora, Chiapas, Campeche, Durango, Guanajuato, Guerrero, Jalisco, Nayarit, territorio de Quintana Roo, San Luis Poto- 
sí, Yucatán, Tabasco, Veracruz, Ta. maulipas y territorio de la Baja California. $175 \mathrm{ff}$.

24-6-25

1926. Compañía Telefónica de Chihuahua S.A. Tomás Dale, representante de dicha compañía solicita permiso para reformar su escritura social. 34-PB-8

1926. Ferrocarril Chihuahua y Oriente S.A. Permiso para reformar su escritura social. PB-409-49

1926. Compañia de Ferrocarril Chihuahua y Oriente S.A. [solicita] permiso para reformar su escritura social. 28-PB-13

1927. Eduard J. Creel pide permiso para reformar la escritura de la Compañia Eléctrica y de Ferrocarriles de Chihuahua. 199-PB-6

1927. [La] Chihuahua Investment Co., S.A. solicita permiso para reformar su escritura social. 34-PB-6

1927. Casas Grandes, Chihuahua. Protocolización de escrituras por el Registro Público de la Propiedad. 30-17-285

1928. Enrique Seggerman solicita permiso para adquirir bienes para la Compañía Paso del Norte S.A. 310-PB-90

1929. [La] Secretaría de Comunicaciones consulta si hay inconveniente en que se explote el servicio telefónico entre Ojinaga y Presidio. 107-PB-3

1929. Apertura de la aduana de Ciudad Juárez. IV-28-4

1930. Consulta del delegado de migración en Ciudad Juárez sobre visa a los pasaportes chinos [expedida] por el consulado de México en Yokohama, Japón. IV-396-40
1930. La Contraloría de la Federación solicita a la Secretaría de Relaciones Exteriores [le informe sobre] la ac. tual adscripción de Ángel Cordero, quien perteneciera a las fucrzas irregulares en Palomas, Chihuahua. IV-64-58

1930. [La] Secretaría de Hacienda y Crédito Público autoriza la exención de derechos de importación a juguetes y ropa, importados por el Comité Pro Navidad del Niño Pobre, donados a los niños del estado de Chihuahua.

\section{53.7}

1931. La aduana de Ojinaga informa sobre manifiestos consulares legalizados por el consulado en Presidio, duran. te el mes de enero. IV-541-8

1931. Informes sobre turismo en el estado de Chihuahua.

$$
\text { Iv-493-14 }
$$

1931. La Secretaría de Agricultura remite [información sobre la] distribución geográfica de [la] fauna silvestre en el estado de Chihuahua. Iv-607-21

1932. La aduana de Ojinaga informa sobre manifiestos consulares legalizados por el consulado de Presidio, durante el mes de marzo. IV.541-7

1932. La aduana de Ojinaga informa sobre manifiestos consulares legalizados por el consulado de Presidio, durante el mes de marzo.

$$
\text { IV.541.9 }
$$

1934. El señor C. Eastiand, gerente del First State Bank, solicita informes sobre el requisito para la instalación de una estación radiodifusora en Ojinaga, Chihuahua. III-294-33

1938. Informes sobre la huelga [de los trabajadores] de la empresa luz y Fuerza de Ciudad Juárez. 

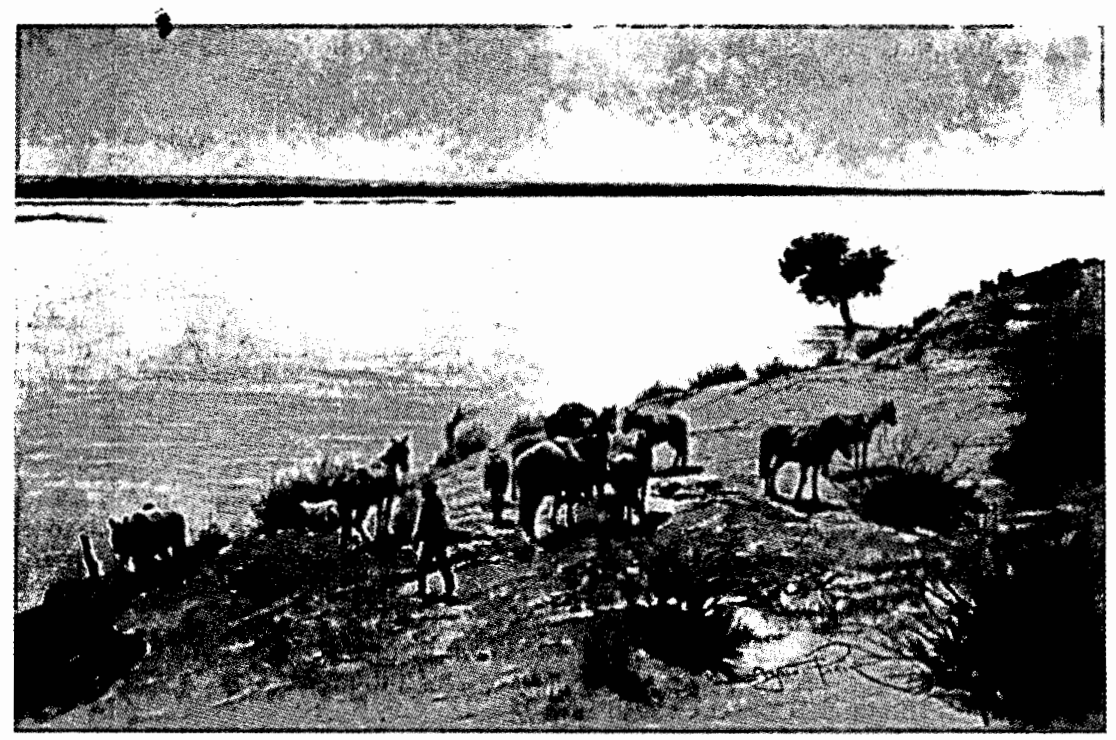

1.6.10 Actividades comerciales y culturales.

1838. [Noticia sobre el] archivo del colegio de ex jesuitas [de Chihuahua]. I-3-803

1881. Permiso a Mariano Samaniego para poner un puente provisional sobre el río Bravo durante la feria de Paso del Norte. 4.1.5517

1923. Exposición Comercial Artística del Centro Chihuahuense. 38-11.74

1929. Reunión de agraristas en [Ciudad] Cuauhtémoc, Chihuahua. LE-696 (7)

1931. Tercera Feria Regional de Chihuahua, organizada por el Club Rotario de [la] ciudad de Chihuahua. IV-489-21

1935. Informes sobre apertura de casas de juego en Ciudad Juárez.

III-315-21

1936. La Cámara de Comercio de Ciudad Juárez, solicita no se restrinja la importación de mercancías a Estados Unidos.

III-239-4

1939. Informe sobre [la] audición [de] la banda de música de la primera división de caballería del ejército norteamericano en Ciudad Juárez. III-404-36

1948. Informes sobre el congreso agrario que tendrá lugar en la ciudad de Chihuahua en el mes de julio.

III-1620-16

1948. Expedición científica en Chihuahua encabezada por el señor Robert A. McCabe. III-1190-3

1962. Informes y todo lo relacionado con la exploración geológica para co- 
lectar fósiles en los estados de Chihuahua y Guanajuato.

\subsection{Cancillería de México.}

1.7.1 Instrucciones.

1933. [Chihuahua] Sobre gestiones del licenciado Federico Sodi para obtener divorcios en el extranjero e instrucciones de esta secretaría impidiendo tan indebido proceder. III-124-7

1.7.2 Asuntos políticos, documentos, estudios y correspondencia.

1920. Correspondencia particular del C. Cutberto Hidalgo, secretario de Relaciones Exteriores con Francisco Villa. 6-11-216

2. Chihuahua/México y sus relaciones con Estados Unidos.

2.1 Límites.

2.1.1 Documentos, estudios y correspondencia.

1853. Correspondencia de el gobernador de Chihuahua y la legación de Estados Unidos relativa al derecho que estos últimos pretenden tener sobre La Mesilla. 1.2-566

1858. Correspondencia relativa a la propuesta del ministro de Estados Unidos, John Forsyth, sobre una nueva demarcación de límites.

$$
\mathrm{x}-2.9
$$

1862. Correspondencia entre el general H. Sibley y el gobernador del estado citado [Chihuahua] con motivo de la invasión del territorio mexicano por los confederados del Sur.

11-H.I-4

1887. Proyecto de desagüe de la ciudad de El Paso, Texas y perjuicios que ocasionará a Paso del Norte.

$$
\text { 41.24-1 }
$$

1892-95. Convención para la construcción de una presa internacional sobre el río Bravo, cerca de El Paso, Texas. Correspondencia relativa a las negociaciones entre México 1897 $1895-96$ 1901 y Estados Unidos ( 6 partes).

$1996-97$

1901-1903

$1903-1906$

$$
\begin{aligned}
& x-7-2 \\
& x-8-1 \\
& X-9 \cdot 1
\end{aligned}
$$

1932. Acuse de recibo de noticias de prensa sobre El Chamizal ( 25 de octubre). A-1022 (minutas 401 a 600 )

1939. Memorándum sobre la situación de la frontera en Ciudad Juárez y valles bajos del [río] Bravo (26 de diciembre). A-102-6

1941. Relaciones o listas de expedientes históricos que se encuentran en la sección de límites.

30-29.181

2.1.2 Planos, mapas y croquis.

1893-1929. Mapas y planos para la Comisión Internacional de Límites entre México y Estados Unidos. Se fija la línea divisoria de acuerdo con el tratado del 2 de febrero de 1848 . Solicitudes, adquisiciones, remisiones y todo lo relacionado con este asunto.

$$
\mathrm{x} \cdot 9 \cdot 2
$$

2.1.3 Fugitivos, invasiones e incursiones.

1846. Consulta el gobernador de Chihuahua sobre planes de defensa y medidas que deben tomarse contra los extranjeros sospechosos que se introduzcan en el estado, dada la guerra que existe con Estados Unidos.

$$
\text { 1.11-1148 }
$$

1850. El gobierno de Chihuahua da cuen- 
ta de los abusos cometidos en la villa de El Paso por una partida de $\mathbf{3 0 0}$ aventureros norteamericanos que pasaban para California. ff. 1-14.

29-15.46

1853. Violación del territorio mexicano por aventureros norteamericanos que asaltaron la cárcel de Paso del Norte con el fin de sacar a su conciudadano Meyer. ff. 15-40. 29-15-46

1862. Correspondencia entre el general H. Sibley y el gobernador del estado citado [Chihuahua] con motivo de la invasión del territorio me. xicano por los confederados del Sur.

11+H-I-4

1865. Datos e informaciones del gobernador de Chihuahua sobre combates entre los vecinos de Paso del Norte $y$ aventureros texanos.

\section{$1-2-571$}

1877. El presidente municipal de Villa de Guerrero, comunica noticias sobre la violación del territorio mexicano por americanos, los cuales asaltaron el rancho de Paso de los González.

$$
\text { 29-15-46 }
$$

1878. Correspondencia entre las autoridades militares de México y la legación, también de México, en Estados Unidos para la persecución de indios bárbaros.

$$
\text { 1-14-1615 }
$$

1879. Depredaciones de indios bárbaros en la frontera entre Estados Unidos y México.

$$
\text { 29-15-45 }
$$

1879-82. Depredaciones cometidas por indios mezcaleros $\mathrm{y}$ apaches cerca de La Mesilla, desertores de las reservaciones cercanas al fuerte Stanton, Nuevo México. Probable incursión de éstos en territorio de Chihuahua.

$$
\text { 20-23-60 }
$$

1881. Asesinatos de varias personas en Chihuahua atribuidos a los apaches. 25-20-193

1881. Robos de ganado a la propiedad de los señores Herrera y González de Chihuahua, cometidos por bandidos americanos. 4-16-24

1881. Ganado robado en Chihuahua y conducido al rancho de Santa Teresa [Estados Unidos]. 41-16-23

1881. Sucesos ocurridos en Paso del Norte con motivo de la fuga intentada por siete criminales americanos. 41-16-22

1882-87. Exposición de los representantes de Chihuahua en el Congreso de las Unión (Eduardo Urrueta y Fernández, R. Guerrero y M. León) sobre las últimas depredaciones cometidas por los indios bárbaros procedentes de las reservaciones americanas y gestiones de Matías Romero (ministro de México en Estados Unidos) ante el citado gobierno. $132 \mathrm{ff}$. 20.23-61

1883. Correspondencia entre la legación de México en Washington y el Departamento de Estado de Estados Unidos, relativa a depredaciones de los indios apaches y chiricachuas en Sonora y Chihuahua.

$$
\text { 35.15.34 }
$$

1913. Comunica desde Hermosillo, Sonora, Rafael Múzquiz [sobre] falsas noticias [que] explota [la] prensa amarilla [de] Estados Unidos sobre supuestos actos vandálicos del general Villa.

$$
\text { 36-30-13 }
$$

1916. Creación de la Comisión Unida Mexicano-A mericana para tratar de re. solver las reclamaciones surgidas por la invasión del territorio americano por el general Francisco Villa (2 partes). 


\section{$17 \cdot 11 \cdot 185$}

1918. Filibusteros en Presidio, Texas. L-E-858 (4)

1919. Columbus, Nuevo México. Incursión y matanza por Francisco Villa. L-E-838 (3)

1929. Derechos consulares y aduanales para agentes rebeldes en El Paso, Texas.

L-E-696 (1)

2.1.4. Informes sobre linderos fijación de la línea fronteriza y monumentación.

1850. Ejidatarios de los pueblos [ubicados] entre Chihuahua y Estados Unidos. Gestiones de los mismos para que se definan los límites con Esta. dos Unidos y sus derechos de propietarios. $\mathrm{x}-2-3$

1855. Límites entre México y Estados Unidos. Trabajos de la sección mexica. na ante la Comisión de Límites con Estados Unidos. Demarcación de límites internacionales. $\mathrm{x}-2-6$

1881. Comisión de ingenieros para la reposición de los monumentos en la línea divisoria con Estados Unidos de A mérica.

Leg. 3185-al 3

3186-al 3

3187-al 4

3188-al 4

1890. Límites entre México y Estados Unidos en el río Bravo. Gestiones de México para que las autoridades locales [establecidas] a lo largo del río, se abstengan de tratar cuestiones de límites. $\mathrm{x}-6-2$

1893-1929. Mapas y planos para la Comisión Internacional de Límites entre México y Estados Unidos. Se fija la línea divisoria de acuerdo con el tratado del 2 de febrero de 1848 . Solicitudes, adquisiciones, remi- siones y todo to relacionado con este asunto.

$\mathrm{x}-9-2$

1894. Línea divisoria internacional entre Ciudad Juárez, Chihuahua y El Paso, Texas. Gestiones del gobierno de Es. tdos Unidos para que se determine la citada línea. $\mathrm{X} \cdot 9 \cdot 4$

1895-99. Eliminación de bancos en los ríos [limítrofes de México] y Estados Unidos. Informes, estudios y datos tomados en consideración para una nueva convención sobre la materia ( 3 partes).

$\mathrm{x} \cdot 10-4$

$\mathrm{x} \cdot 11 \cdot 1$

1900. Proyecto de la presa internacional (sobre la cuestión de limites fluviales entre México y Estados Unidos) realizado por el ingeniero Jacobo Blanco. Se incluyen fotografias. $f$. 5. LE-1162

\subsubsection{Negociaciones.}

1892-95. Convención para la construcción de una presa internacional sobre el río Bravo, cerca de El Paso, Texas. Correspondencia relativa a las negociaciones México y Estados 1895-96 Unidos (6 partes.)

$1896-97$

$1897-1901$

1901-1903

1903-1906 x-7.2. $x-8-1$

$$
\mathrm{x} \cdot 9-1
$$

1938. Pláticas que se están celebrando en Washington sobre la cuestión de el Chamizal.

$$
\text { A-108-11 }
$$

1943. Ciudad Juárez, Chihuahua. Proyecto escrito para llegar a un acuerdo entre México y Estados Unidos sobre el reparto de aguas, obras y operación de sistemas en la fron- 
tera (28 de septiembre). A-88-2

\subsubsection{Reclamaciones.}

1906-1909. Canal en construcción del lado norteamericano frente a la presa de el Paso, Texas. Protesta de los ribe. reños mexicanos con motivo de los perjuicios que les ocasiona dicho canal.

$$
\mathrm{x}-27 \cdot 3
$$

1910. Alegato que el gobierno de México presenta al de Estados Unidos conforme al articulo quinto de la Convención de Arbitraje para el caso de El Chamizal.

28-14-133

1911. Litigio por limites entre México y Estados Unidos de A mérica en lo referente a El Chamizal.

$$
\text { 13-14-79 }
$$

1916. Creación de la Comisión Unida Mexicano-Americana, para tratar de resolver las reclamaciones surgidas por la invasión del territorio americano por el general Francisco Villa.

$$
\text { 17.11-185 }
$$

1924. Los herederos de Pedro Ignacio García presentan [la] reclamación [núm.] 1290 por los terrenos de El Chamizal.

$$
\text { C-3-2-106 }
$$

1937. Proyecto de reformas al Tratado de Límites entre México y Estados Unidos.

$$
\text { III. 1906-2 }
$$

1964. Diversas reclamaciones de personas que creen tener derechos de tierras de El Chamizal. III/2961.1

2.1.7 Representantes.

1906. José Ramón de Ibarrola es nombrado jefe de la Comisión Mexicana de Límites con Estados Unidos. 20-19. 24

2.1.8 Obras de infraestructura.
1881. Se concede permiso a la Compañía Constructora Internacional para la construcción de un ferrocarril de México a El Paso. 4.2-5605

1886. Obras del ayuntamiento de El Paso, Texas que obstruyen el cauce del río Bravo. Gestiones de la Comisión Internacional de Límites para que sean retiradas esas obras. $\mathrm{x} \cdot 3 \cdot 8$

1887. Proyecto de desagüe de la ciudad de El Paso, Texas y perjuicios que ocasionará a Paso del Norte. 41-24.1

1892-95. Convención para la construcción de una presa internacional sobre el rio Bravo, cerca de El Pa. so, Texas. Correspondencia relativa a las negociaciones entre Méxi$1895-96$ co y Estados Unidos (6 partes).

$1896-97$

$1897-1901$

$1901 \cdot 1903$

1903.1906

$x \cdot 7 \cdot 2$

$x \cdot 8 \cdot 1$

$x \cdot 9 \cdot 1$

1900. Proyecto de presa internacional (sobre la cuestión de límites fluviales entre México y Estados Unidos) realizado por el ingeniero Jacobo Blanco. Se incluyen fotografias. $15 \mathrm{ff}$. L.E. 1162

1906-1909. Canal en construcción del lado norteamericano frente a la presa de El Paso, Texas. Protesta de los ribereños mexicanos con motivo de los perjuicios que les ocasionará dicho canal. $\mathrm{x}-27-3$

1929. Línea telefónica entre Ojinaga, Chihuahua, y Presidio, Texas. IV-260-19

1943. Ciudad Juárez, Chihuahua. Proyecto escrito para llegar a un acuerdo entre México y Estados 
Unidos sobre el reparto de aguas, obras y operación de sistemas en la frontera (28 de septiembre). A-88-2

2.1.9. Comisión de Límites.

1833. La Comisión de Límites manifiesta que nada sabe sobre el pago con tierras que Chihuahua debe hacer al gobierno de la federación.

\subsection{3 .4983}

1886. Obras del ayuntamiento de El Paso, Texas que obstruyen el cauce del río Bravo. Gestiones de la Comisión Internacional de Límites para que sean retiradas esas obras. $\mathrm{x} \cdot 3 \cdot 8$

1891. Memoria de la Comisión Internacional de Límites entre México y Estados Unidos. $\mathrm{x}-6.4$

1893-1929. Mapas y planos para la Comisión Internacional de límites entre México y Estados Unidos. Se fija la línea divisoria de acuerdo con el tratado del 2 de febrero de 1848 . Solicitudes, adquisiciones, remisiones y todo lo relacionado con este asunto.

$\mathrm{x}-9-2$

1894. Caso "Jetties", "Presidio" e "Isleta", en los limites con Estados Unidos, sometidos a la consideración de la Comisión Internacional de Límites.

$\mathrm{x}-9-7$

1900. Basurero de El Paso, en la margen del río Bravo. Gestiones de la Comisión Internacional de Límites para que se defina su ubicación. $\mathrm{x}-24-1$

1900-07. Facultades y funciones de la $\mathrm{Co}$ misión de Límites y Aguas MéxicoEstados Unidos, definición de las mismas. $\mathrm{X}-27-5$

1906. José Ramón de Ibarrola es nombra. do jefe de la Comisión Mexicana de
Límites con Estados Unidos.

20-19-14

1906. Investigaciones de la Comisión de Límites para conocer el paradero de los documentos sobre exploraciones geográficas del teniente norteamericano Zebulon Montgomery Pike.

6-4-22

1906-09. Correspondencia entre la Comisión de Límites de México con Estados Unidos y la SRE. Índices y registro de la misma (4 partes). $\mathrm{x}-29-1$

1916. Comisión Internacional de Límites en El Paso, Texas. LE-801 (32)

1920. Aduana fronteriza de Ciudad Juárez, Chihuahua. Remesas de fondos a la Comisión Internacional de Límites.

21.8.82

1922. Informes sobre demora de mensajes oficiales de la Comisión Internacional de Límites México-Estados Unidos. 18.5.58

1930. Envío a esta Secretaría de un ejem. plar de la memoria de la Comisión Internacional de Límites entre México y Estados Unidos.

$$
\text { 11-3-240 }
$$

1936. Se informa sobre documentación referente a $\mathrm{El}$ Chamizal que se encuentra en los archivos de la Comisión Internacional de Límites (18 de noviembre).

$$
\text { A-100-8 }
$$

1967. Acto por medio del cual se aprueba el acta número 228 de la Comisión Internacional de Límites y Aguas entre los Estados Unidos de América. Realizado en Washington el 27 de octubre.

EUA-112 (VII)

2.1.1 Acuerdos, convenciones, convenios y tratados. 
1848. Tratado de Paz, Amistad, Limitesy Arreglo Definitivo entre México y los Estados Unidos de América. Firmado en Guadalupe Hidalgo, D. F., el 2 de febrero de 1848 (copias del mismo y otros documentos). $\mathrm{x}-14-1$

1848. Tratado de Paz, Amistad, Límitesy Arreglo Definitivo entre México y los Estados Unidos de América. Fir. mado en Guadalupe Hidalgo, D. F., el 2 de febrero de 1848. Correspondencia relacionada con los límites entre ambos países.

$\mathrm{x}-14-2$

1848. Tratado de Paz, Amistad, Limites y Arreglo Definitivo entre México y Estados Unidos de América. Firmado en Guadalupe Hidalgo, D. F., el 2 de febrero de 1848. Documentos sobre el mismo, pedidos por una comisión del Senado de México. $x-14-3$

1848-55. Límites entre México y Estados Unidos. Trabajos de la Comisión de Límites entre ambos países, de conformidad con el Tratado de Paz, Amistad, Limites y Arreglo Definitivo. Firmado en Gudalupe Hidalgo, D. F., el 2 de febrero de 1848 y ratificado en Washington el 10 de mar. zo de ese mismo año.

$\mathrm{X}-\mathrm{I}-11$

1853. Tratado de Límites y Amistad entre México y Estados Unidos de América. Firmado en México el 30 de diciembre de 1853.f. 56.

\section{1-1.82}

1854. Tratado de Amistad y Limites en México y Estados Unidos de América. Firmado en la ciudad de México el 30 de diciembre de 1853; [se refiere a] la enajenación de La Mesilla y [contiene] artículos aclaratorios

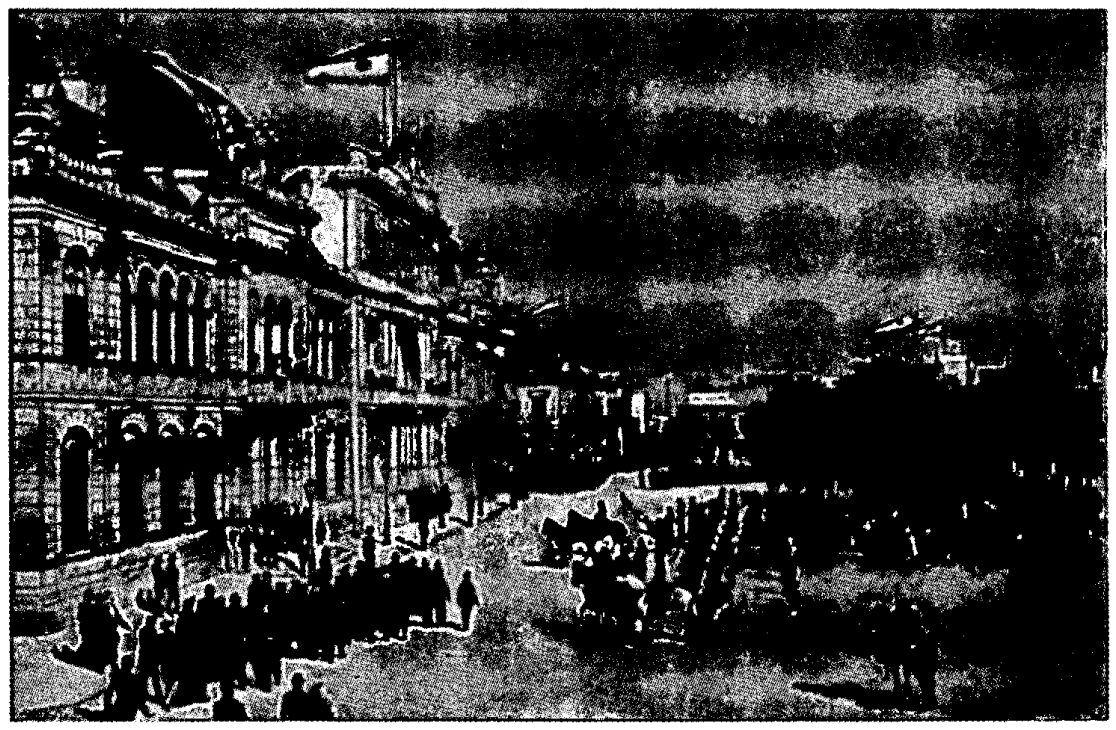


adicionales al tratado de Guadalupe Hidalgo.

$\mathrm{x}-14-4$

1882-87. Convención firmada en Washington, el 29 de julio de 1882, entre México y Estados Unidos, para establecimiento de una Comisión Internacional de Limites. Se pide prórroga de plazo sobre la reposición de las mojoneras de El Paso del Norte al Pacífico. $\mathrm{x} \cdot 3-6$

1888-1892. Convención para establecer 1895-1898. la Comisión. Internacional de 1898-1901. Límites entre México y Estados Unidos. Firmada en la ciudad de Washington el 1 de marzo de 1889 , [con] prórrogas anuales hasta el año de 1900 (3 partes). $x-5-1$

1892-95. Convención para la construcción de una presa internacional sobre el rio Bravo, cerca de El Paso, Texas. Correspondencia relativa a las negociaciones entre México y Es1895.96 tados Unidos ( 6 partes).

1896.97

1897.1901

1901-1903

1903-1906

$\mathrm{x}-7-2$

$x \cdot 8-1$

$x \cdot 9-1$

1899. Tratado para la organización de la Comisión Internacional de Límites entre México y Estados Unidos. Renovación del citado tratado que se firmó en la ciudad de Washington, $D$. C. el 29 de julio de 1882 . $\mathrm{x}-14.5$

1910. Convencion para terminar con las diferencias respecto del dominio eminente sobre el territorio de $\mathrm{El}$ Chamizal entre Estados Unidos Mexicanos y Estados Unidos de América. Firmada en Washington el 24 de junio.
EUA-37 (I)

1918-19. Tratado de Limites y Distribución Equitativa de las Aguas de los Ríos Bravo y Colorado entre México y Estados Unidos. Proyecto para la elaboración de uno nuevo y gestión de la Comisión de límites de ambos países. $\mathrm{x}-14-6$

1938. Acuerdo entre México y Estados Unidos sobre distribucion de aguas en Valle de Juárez (25 de agosto). A-100-8

1941-47. Tratado para la Distribución de Aguas Internacionales entre México y Estados Unidos. Firmado en la ciudad de Washington, D. C. el 3 de febrero de 1944 (25 partes).
$\mathrm{x} \cdot 14-10$
$\mathrm{x}-15 \cdot 1$
$x-16-1$
$x-17-1$
$\mathrm{x}-18 \cdot 1$
$\mathrm{x}-19-1$
$\mathrm{x}-20-1$
$\mathrm{x}-2 \mathrm{I}-1$
$\mathrm{x}-22-1$
$\mathrm{x}-23-1$

1963. Convención para la solución del problema de El Chamizal entre Estados Unidos Mexicanos y Estados Unidos de América. Firma. da en México el 29 de agosto de 1963.

$$
\text { EUA-112-(III) }
$$

1963. Convención entre Estados Unidos Mexicanos y Estados Unidos de América para la solución del problema de El Chamizal. Correspondencia relacionada con el problema de El Chamizal ( 2 partes).

$$
\text { A.635-1 }
$$

2.2 Actividades diplomáticas.

2.2.1 Visitas.

1932. Reunión en El Paso de los goberna- 
dores Texas y Chihuahua (18 de marzo).

A-1021

(minutas 1 a 200)

1964. El Chamizal. Ceremonia del 25 de septiembre de 1964, para señalar simbólicamente el nuevo curso del río Bravo. Documentos relativos al problema ( 2 partes). A-636-1

1964. Entrevista Díaz Ordaz-Johnson, celebrada del 26 al 28 de octubre de 1967 [asunto de El Chamizal]. A727-A

1967. Declaración sobre la transferencia de El Chamizal, de los presidentes de Estados Unidos Mexicanos, Gustavo Díaz Ordaz, y de Estados Unidos de América, Lyndon B. Johnson firmada en Ciudad Juárez el 28 de octubre.

EUA-112 (IX)

2.2.2 Reclamaciones.

1848-49. Se ponen en conocimiento del gobierno de Estados Unidos los atentados que los norteamericanos cometen en los bienes y personas de los mexicanos en Chihuahua.

6-17.39

2.2.3 Acuerdos, convenciones, convenios y tratados.

1882. Convenio que autoriza el paso de tropas de los respectivos gobiernos, por la linea divisoria internacional, en persecución de indios salvajes entre Estados Unidos Mexicanos y Estados Unidos de A mérica. Firmado en Washington, D. C. el 29 de julio.

EUA-23-(1)

1881-90. Convención para el paso recíproco de tropas en persecución de indios bárbaros. Celebrada en la ciudad de México y firmada el 29 de julio de 1882 en dicha ciudad. f. 884.
L-E-2242 (la vi pte.)

1888. Arreglo entre México y Estados Unidos para el paso recíproco de ganado.

7.11-13

1888. Arreglo México-Estados Unidos sobre el paso recíproco de ganado.

7-19-18

1890. Convenio autorizando el paso recíproco provisional de la línea di. visoria internacional de tropas de sus respectivos gobiernos, en persecución de indios salvajes sublevados. Firmado en Washington, D. C. el 25 de junio.

EUA-29 (I)

1896. Convenio autorizando el paso recíproco provisional de la línea divisoria internacional de tropas de sus respectivos gobiernos, en persecución de la banda de indios sublevados de Kid. Firmado en Washington, D. C. en junio.

EUA-30-(I)

1916. Protocolo de convenio ad-referéndum sobre el retiro de las fuerzas americanas de territorio mexicano y protección de la frontera internacional entre Estados Unidos Mexicanos y Estados Unidos de América. Firmado en Atlantic City, Nueva Jersey el 24 de noviembre.

EUA-30-(I)

1925. Convención celebrada entre Estados Unidos Mexicanos y Estados Unidos de América sobre importación ilegal de mercancías, narcóticos $y$ otros productos, mi. gración ilegal de extranjeros y pesca.

11-13.75

1931. Reglamento especial que rige el movimiento de ganado en pie entre Estados Unidos y México. IV.252-15

1964. Acuerdo sobre el nivel de las futuras exportaciones de carne de res 
$y$ de ternera de Estados Unidos Mexicanos con destino a Estados Unidos de América. Celebrado por canje de notas en Washington, D. C. el 14 de mayo.

EUA-113-(I)

1966. Acuerdo para la creación de una comisión conjunta para elevar, mediante la cooperación reciproca, el nivel de vida de las comunidades a lo largo de la frontera entre Estados Unidos Mexicanos y Estados Unidos de América. Celebrado por canje de notas en México entre el 30 de noviembre y el 3 de diciembre.

$$
\text { EUA-119 (I) }
$$

1970. Acuerdo que regula la exportaciôn de carne durante el año calendario de 1970 de Estados Unidos Mexicanos a Estados Unidos de América. Celebrado por canje de notas en México el 20 de marzo.

$$
\text { EUA-130 (I) }
$$

1972. Acuerdo que regula la exportación de carne durante el año calendario 1972 de Estados Unidos Mexicanos a Estados Unidos de América. Celebrado por canje de notas entre el 17 y 26 de abril.

EUA-135-(1)

1976. Acuerdo sobre la asistencia mutua entre los servicios de aduanas, de los gobiernos de Estados Unidos Mexicanos y de Estados Unidos de América. Firmado en México el 30 de septiembre.

$$
\text { EUA-140-(I) }
$$

1983. Convenio sobre cooperación para la protección y mejoramiento del medio ambiente en la zona fronteriza entre Estados Unidos Mexicanos y Estados Unidos de América. Firmado en La Paz, Baja California, el 14 de agosto.

$$
\text { EUA-160-(I) }
$$

\subsection{Asuntos políticos.}

\subsubsection{Política exterior.}

1877-1878. Grupos sediciosos [en] El Paso, Texas. LE-64

1906. Movimientos de la Junta Revoluciona. ria [magonistas] en El Paso, 'Texas. LE-862 (2)

1910. Agentes de Francisco I. Madero en Presidio, Texas. LE-613

1910-11. Club maderista en el Paso, Texas. L.E-690

191 1. El Paso, Texas. Fuga de Francisco I. Madero. L-E-633 (1)

1911. Revolucionarios [en] Columbus, Nuevo México (periódico). L-E-646

1912. Movimiento orozquista. Aprehensión [de] agentes. L-E-832 (1)

1914. Prohibición de la venta [de] armas en Presidio, Texas. L-E-813

1914. Rebeldes en El Paso, Texas. Su vigilancia. L-E-856 (4)

1916. Reunión del partido científico en El Paso, Texas. L-E-800 (1) (2)

1916. Manifestación en contra de la intervención americana en Parral, Chihuahua. L.E-800 (3)

1916-17. Agencia secreta en el Paso, Texas. L-E-724 (1)

1917. Movimiento sedicioso [en] El Paso, Texas. L-E-838 (4)

1918. Propaganda felicista en El Paso, Texas. L-E-858 (4)

1918. Villistas en Presidio, Texas. L-E-837 (12)

1920. El consulado en Presidio envía informes sobre movimientos rebeldes de Francisco Villa. 
17.17.305

1924. Actividades de Rosalío Hernández en El Paso, Texas (14 de junio).

\section{A.824}

(minutas 501 a 600)

1924. Disgustos surgidos entre delahuertistas residentes en El Paso, Texas (16 de mayo).

\section{A-824}

(minutas 301 a 400)

1960. Informe de la sección local del sindicato de la radiodifusión, sobre las publicaciones denigrantes [sobre] Ciudad Juárez, hechas por el señor Jesús Buenrostro en la radiodifusora de El Paso, Texas. III-2297-6

1964. Queja del senador por el estado de Texas, Ralph W. Yasborovoh, acerca de ataques hechos en su contra por un enemigo suyo en el curso de la última campaña política de Texas, desde una estación de radio de Ciudad Juárez, Chihuahua.

III-2998-18

1969. Declaración conjunta sobre el control del tráfico ilegal de estupe. facientes, mariguana y otras drogas peligrosas de las delegaciones de Estados Unidos Mexicanos y de Estados Unidos de América. Firmada en México el 30 de octubre.

$$
\text { EUA-129-(1) }
$$

\subsubsection{Noticias, reseñas e informes.}

1850. El gobierno de Chihuahua da cuenta de los abusos cometidos en la villa de El Paso por una partida de 300 aventureros norteamerica. nos que pasaban para California. $f$. $1 \cdot 14$.

$$
\text { 29-15-46 }
$$

1865. Datos e informaciones del gobernador de Chihuahua sobre combates entre los vecinos de Paso del Norte $y$ aventureros de Texas.

$$
\text { 1.2-571 }
$$

1866-88. El gobernador del estado de Chihuahua envía a la SRE informes sobre los norteamericanos presos en Chihuahua.

$$
\text { 20-23-78 }
$$

1874. Informe que en cumplimiento de su encargo rinde al gobierno la comisión investigadora en Sonora y Chihuahua.

$$
\text { LE-1101 }
$$$$
\text { L.E-1402 }
$$

1897. El gobernador del estado de Chihua. hua informa sobre la prohibición del gobierno americano para que los chinos entren en Estados Unidos.

$$
\text { 15.7.94 }
$$

1911. Informes de los movimientos ocurridos en Ciudad Juárez, Chihuahua.

$$
\text { LE-685 (5) }
$$

1913-1917. Informes sobre los movimien. tos villistas.

$$
\begin{aligned}
& \text { L-E-799 (8) } \\
& \text { L-E-783 (3) } \\
& \text { L-E-770 (1) }
\end{aligned}
$$

1916. Informes sobre movimiento de re. beldes en el norte, rendidos por $F$. J. Stof ka y un coronel villista.

17.9.15.2

1919. Informes sobre movimientos de Francisco e Hipólito Villa. 17-16-203

1919. Informes sobre movimientos rebeldes en Ojinaga.

17-16-180

1919. Informes sobre norteamericanos en Chihuahua.

16-30-95

1919. Movimiento de Francisco Villa y otro general. Informe sobre ayuda [que] imparten las compañías petroleras.

$$
\text { 17-16-164 }
$$

1931. El gobierno de Chihuahua informa sobre [el] arribo de numerosos compatriotas [deportados, de paso por] Ciudad Juárez.

IV.343-6

\subsection{Asuntos militares.}


1847. Chihuahua. Implicación en la guerra contra Estados Unidos. 1.2.327

1892-70. Convención para el paso reci. proco de tropas en persecución de indios bárbaros. Celebrada en la ciudad de México y firmada el 29 de julio de 1882 en dicha ciudad. $f$. 884.

$$
\text { LE-2242 (I a vi pte) }
$$

1892, 1911, 1913. Trámites legales para el cruce de tropas mexicanas por territorio de Estados Unidos.$$
766 \text { (16), } 763(6)
$$

1911. Batalla [en] El Paso, Texas. L-E-623 (1)

1914. Armamento del gobierno mexicano decomisado por autoridades americanas en Presidio, Texas. L.E-768 (5)

1915. Enfrentamiento militar entre tropas americanas y revolucionarios villistas.

L-E-730 (2)

1915. Ejército Constitucionalista en $\mathrm{El} \mathrm{Pa}$ so, Texas. L-E-809 (2)

1916. [Incidente] motivado por la incursión de Francisco Villa a territorio americano. Documentación relacionada con el caso, así como la que resultó de la incursión punitiva a México al mando de John J. Pershing. Dictamen de la delegación mexicana [a] la Junta México-Americana.

7-9-14

1916. Movimiento villista. Asesinato de norteamericanos en Santa Isabel. L-E-868A

1916. Telegramas dirigidos al primer jefe del Ejército Constitucionalista, sobre el ataque de Francisco Villa a la ciudad de Columbus. L-E-1443

1916. Regimiento americano. Su salida de Chihuahua. L.E-800 (3)
1916. Ataque de Villa [a] Columbus. LE-801 $(17,27)$

1916. Estados Unidos recluta gente para combatir a Villa. LE-801 (31)

1919. Incidente internacional con motivo del ataque de los villistas a Ciudad Juárez.

17.6-141

1919. Persecución de Francisco Villa por tropas mexicanas en la frontera de Nuevo México. L-E-838 (3)

1919. Tropas mexicanas en la frontera de Arizona, Nuevo México y Texas en persecución de Francisco Villa. L.E-838 (3)

1922. Consulta de expedientes relativos al ataque a Columbus por Francisco Villa y la incursión punitiva del ge. neral Pershing [realizada] por el mayor Silvino M. González.

III*123.24

2.5 Asuntos económicos.

1913. Compra de armas y parque en El Paso, Texas. LE-761 (14)

1916. Hacen preguntas los representantes americano e inglés acerca de los billetes emitidos en los estados de Sonora y Chihuahua y exportación de billetes de banco. 16-16-73

1934. Solicitud para exportar hielo de Ciudad Juárez a El Paso, Texas. 20-22-25

1939. Gestiones para reducir los impuestos por concepto de exportación de ganado mexicano a Estados Unidos. III-414.17

2.6 Actividades consulares.

2.6.1 Migración.

1877. Una partida de indios mezcaleros solicita terrenos baldios cerca de Ojinaga para establecerse. 2-1-1782 
1911. Chihuahua. Emigraciones a Estados Unidos. L-E-688 (2)

1916. Ciudadanos americanos en Chihuahua.

$$
\text { L-E-800 (2) }
$$

1916-17. El gobierno de Chihuahua remite lista de los extranjeros americanos residentes en dicho estado. 44-1-23

\subsubsection{Justicia.}

1855. Sucesos ocurridos en unas casas de juego puestas por individuos, al parecer americanos, en Paso del Norte.

15-2-72

\subsubsection{Protección.}

1849. El gobernador de Chihuahua se refiere al traslado de familias mexicanas de Nuevo México de acuerdo con el Tratado de Guadalupe-Hidalgo.

$$
\text { 2.13-2971 }
$$

1866-88. El gobernador del estado de Chihuahua envía a la SRE informes sobre los norteamericanos presos en Chihuahua.

$$
\text { 20-23-78 }
$$

1886. Americanos maltratados por mexicanos en Chihuahua.

$$
\text { 17-21-110 }
$$

1900. Americanos residentes en La Ascensión, Chihuahua, solicitan la devolución de ganado robado. 15.8.116

1911. Captura de americanos en Casas Grandes, Chihuahua.

$$
\text { L-E-648 (I) }
$$

1911. Protección del ferrocarril de Parral a Durango, propiedad de una compañia americana.

$$
16-7.9
$$

1915. Americanos presos en Chihuahua. L-E-810 (1)

1916-17. Queja por atropellos en los bienes del ferrocarril de Parral a Duran. go, propiedad de americanos, por parte de bandoleros.

16-20-219

1918. Queja por perjuicios contra el ferrocarril de Parral a Durango ocasionados por bandoleros. Se pide protección.

\section{3-5.15}

1920. Warner and Company, propietaria del rancho Ojitos, se queja por robos de ganado.

17.12-117

2.6.4 Funciones auxiliares de las demás dependencias del ejecutivo.

1857. El gobernador de Chihuahua da cuenta del permiso concedido a soldados americanos para pasar porterritorio del estado, conduciendo bastimentos.

$$
\text { 6.2-83 }
$$

1881-82. Inocente Ochoa y socios piden permiso para construir un ferrocarril sobre el río Bravo para unir el territorio mexicano con el norteamericano.

$$
\text { 4.1.5518 }
$$

1881-82. Permiso a Salomón Schultz y socios para la construcción de un fe. rrocarril sobre el río Bravo para unir los territorios mexicano y norteamericano.

$$
\text { 4-5-6060 }
$$

1881-86. Se concede permiso a la Compañía Constructora Internacional para la construcción de un ferrocarril de México a El Paso, con un puente sobre el río Bravo. 4-2-5605

1928-29. La Secretaría de Hacienda y Crédito Público informa al secretario de Relaciones Exteriores que el cónsul general de México en El Paso, Texas puede certificar, sin cobrar derechos, la factura que ampara los donativos de ropa, calzado, etc., para los niños pobres de Chihuahua. IV. 55-49 


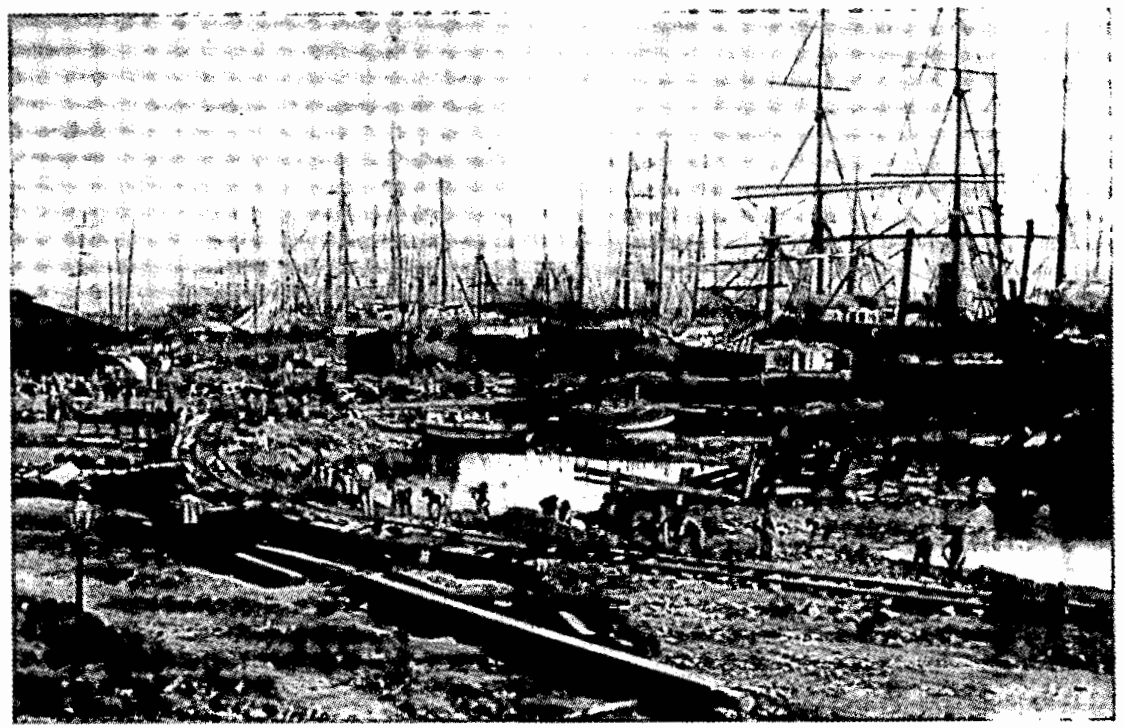

1930. El consulado general de México en El Paso, Texas informa a la SRE de las exigencias de pasaportes por la oficina de migración de Ciudad Juárez, Chihuahua a mexicanos que van a México en calidad de turistas.

IV-89-40

1941. Agradecimiento a los señores Camilo Escalante Patrón y Rodolfo Elizondo, por su ayuda con motivo del aterrizaje forzoso de un avión norteamericano en Ciudad Juárez.

$$
\text { III-603-4 }
$$

1943. Permiso para que un avión norteamericano tripulado por Edwin $M$. Stanton efectúe vuelos entre Chihuahua y Arizona.

III-666-16

1945. Ampliación de viajes por ferrocarril de El Paso, Texas al interior de México.
A-118-1

2.7 Légación de México en Estados Unidos.

2.7.1 Actividades diplomáticas.

2.7.1.1 Correspondencia.

1883. Correspondencia entre la legación de México en Washington y el Departamento de Estado de Estados Unidos, relativa a las depredaciones de los indios apaches y chiricahuas en Sonora y Chihuahua.

35-15-34

2.7.1.2 Negociaciones.

1882-87. Exposición de los representantes de Chihuahua en el Congreso de la Unión (Eduardo Urueta y Fernández, R. Guerrero y M. León) sobre las últimas depredaciones cometidas por los indios bárba. 
ros, procedentes de las reservaciones americanas y gestiones de Matías Romero (ministro de México en Estados Unidos) ante el citado gobierno. $132 \mathrm{ff}$. 20-23-61

\subsubsection{Asuntos políticos.}

2.8.3.1 Política interior.

1893-1907. El consulado de México en El Paso, Texas remite a la Secretaría de Relaciones Exteriores informes sobre el asalto a la aduana de Palomas por los bandoleros Víctor L. Ochoa, Juan Varela, Vicente García y Juan D. Guerra. 44-16-2 (3 partes)

2.8.3.2 Noticias, reseñas e informes.

1913. [El] Consulado de México en El Paso, Texas informa al señor Abraham González acerca de la situación en la capital. 28-9-13

1913-1914. [El] Consulado de México en Brownsville informa del descrubrimiento de las claves telegráficas usadas por los villistas y carrancistas.

28-9-35

1917. [El] Consulado de México en Presidio, Texas informa de los movimientos del rebelde Chico Cano. 28-9-137

1920. Informes de Jesús M. Arriola, comisionado del servicio consular en Los Ángeles, sobre actividades villistas.

9.19-277

2.8.4 Asuntos militares. Noticias, reseñas e informes.

1912. Informes enviados a la Secretaría de Relaciones Exteriores por el consulado de México en Mobile, Estados Unidos, concernientes a los sucesos $e$ investigaciones relacionadas con el contrabando de armas descu- bierto en esa ciudad, destinado a los rebeldes en la ciudad de Chihua. hua.

L-E-827

1912. El cónsul de el Paso [informa] sobre desavenencias de dos oficiales de la guarnición en Ciudad Juárez.

17-17-290

1916. [El] consulado de México en Presidio, Texas comunica que el mayor Gutiérrez se encuentra en la guarnición de Ojinaga. 28-9.115

1917. [El] consulado de México en el Paso, Texas informa de la campaña militar en contra de los villistas.

28-9-147

1919. El consulado en San Francisco informa sobre revolucionarios villistas en Chihuahua.

17.7-216

1920. El consulado en Presidio informa sobre movimiento de rebeldes en Chihuahua. 17.17.299

2.8.5 Asuntos económicos. Noticias, reseñas e informes.

1881. J. Escobar y Armendaul, cónsul mexicano en Franklin, indica la conveniencia de adquirir los aerolitos existentes en Chihuahua, para evitar que se sigan exportando a Estados Unidos.

1.1.157

1908-1910. Informes de los consulados mexicanos en Estados Unidos sobre la solicitud de ciudadanos americanos para la introducción de armas con el objeto de cazar en el estado de Chihuahua. Se comunica sobre la introducción ilegal de cartuchos, carabinas, etc., al territorio nacional, ff. 1-181.

15-20-32

1912. Informes enviados a la Secretaría de Relaciones Exteriores por el consulado de México en Mobile, Estados 
Unidos, concernientes a los sucesos e investigaciones relacionadas con el contrabando de armas descubier. to en esa ciudad, destinado a los rebeldes de Chihuahua.

L-E-827

1917. El consulado de México en Presidio, Texas informa de contrabando de animales de Tinajón o de La Mancha.

28-9-116

1929. El consulado de México en Presidio, Texas informa a la SRE sobre el fraude cometido por el ciudadano español Fidencio Calvo, en perjuicio de comerciantes mexicanos en Chihuahua.

Iv-76-28

1930. El consulado en El Paso, Texas informa sobre la Mexican-International Broadcasting Co., la cual está vendiendo acciones para la construcción de [una] estación difusora en Ciudad Juárez.

IV-287.54

1931. El consulado en Presidio consulta sobre si la cuarentena extraordinaria número 10 , en materia de sanidad vegetal, restringe [la] importación de algodón y sus derivados. IV.457.20

1932. El consulado en El Paso, Texas informa sobre la visita de los gobernadores de Chihuahua y Texas, con motivo de la convención [organizada por la] Cottle Raisers Association.

Iv.333-6

\subsubsection{Actividades consulares.}

\subsubsection{Asuntos administrativos.}

1865. El cónsul en Franklin acusa recibo de la circular [referente al] traslado de[1] gobierno [federal] a Chihuahua, durante la intervención francesa.

$$
3 \cdot 15 \cdot 5370
$$

1913. [El] consulado de México en El Paso, Texas queda enterado de la entrega de armas al jefe de armas en Ciudad Juárez.

28-9.150

1913-1914. Remite el cónsul de México en El Paso, Texas armas para el gobierno de Chihuahua.

28-9-127

1930. El señor José Ornelas, ex agente de migración en Ciudad Juárez, solicita por conducto del consulado general de México en El Paso, 'Texas, a la SRE reconsidere su caso.

$$
\text { IV-64-26 }
$$

1930. La señora Petra Reyes solicita asesoría por conducto del consulado de México en Los Ángeles, California al consulado general de México en El paso, Texas para realizar la remisión de documentos de unas propiedades que posee en Ciudad Juárez, Chihuahua.

IV-91-37

\subsubsection{Sanidad.}

1930. El consulado en El Paso informa que las autoridades americanas han suspendido [el] tráfico entre Palomas y Columbus [a causa de la] muerte de un niño [por] supuesta meningitis.

IV-278-9

1931. El consulado en Presidio consulta sobre si la cuarentena extraordinaria número 10 , en materia de sanidad vegetal, restringe [la] importación de algodón y sus derivados.

$$
\text { Iv-457.20 }
$$

\subsubsection{Protección.}

1928. El cónsul de México en Presidio, Texas informa a la SRE del cobro indebido que se hace a los mexicanos cuando cruzan el puente internacional de Ojinaga a Presidio, Texas.

$$
\text { IV.77-19 }
$$

1930. El consulado general de México en 


\section{SECUENCIA}




El Paso, Texas envía a la SRE la lista de mexicanos aprehendidos durante el mes de agosto y novienbre del presente año, por violación a leyes de neutralidad.

IV-87.9

1930. El consulado general de México en El Paso, Texas envía a la SRE lista de los mexicanos que fueron aprehendidos por haberse internado en forma ilegal a territorio norteamericano en los meses de junio, septiembre y octubre. IV-89.44

1910. Abraham González y Perfecto Lomelí presos [en] Texas. Violación [de las] leyes de neutralidad de Estados Unidos.

L.E-622, 623 (1)

2.8.6.4 Funciones auxiliares de justicia.

1899. El cónsul en Deming participa que allí se encuentra un americano, presunto responsable del homicidio [cometido] en Ojitos, Chihuahua.

17-21-15

1902-03. Exhortos del juez de distrito de Chihuahua [dirigidos] al juez federal del distrito oeste del estado de Texas.

8-28-168

2.8.6.5 Actividades comerciales y culturales.

1929. El consulado en El Paso [informa sobre la] excursión del gobernador de Texas en el estado de Chihuahua. IV-95-28

2.8.6.6 Noticias, reseñas e informes.

1886-88 [Noticias sobre los] procesos judiciales de los norteamericanos presos en el estado de Chihuahua, en. viadas por el gobernador de Chihuahua a la SRE.

20.23.78

1899. El cónsul en Deming informa sobre robo de ganado en el estado de Chihuahua, el cual fue conducido hacia Estados Unidos.

15-8-49

1930. El consulado general de México en El Paso, Texas informa a la SRE sobre la exigencia de pasaportes - por parte de la oficina de migración de Ciudad Juárez, Chihuahua- a mexicanos que van a México en calidad de turistas. IV-89-40

2.9 Embajada de México en Estados Unidos.

Actividades consulares. Actividades comerciales y culturales.

1929. La embajada de Estados Unidos informa sobre el proyecto de la Cámara de Diputados de aquel país, [relativo a la] modificación [de la] tarifa aduanal sobre el tomate y ganado mexicanos. IV. $230-4$

2.10 Consulados de Estados Inidos en Chihuahua.

Actividades consulares. Actividades comerciales y culturales.

2.10.1 Representantes.

1926. Barnet Ridell. Cónsul de Estados Unidos en Chihuahua.

$$
\text { 2-3-2138 }
$$

1826. J. M. Mlasey. Cónsul de Estados Unidos en Paso del Norte, Chihua. hua.

$$
\text { 2-3-2138 }
$$

1849. John S. Lucas. Cónsul de Estados Unidos en Paso del Norte, Chihuahua.

$$
\text { 44.14-86 }
$$

1849. William H. J. Anton. Cónsul de Estados Unidos en Chihuahua. 44-20-89

1850. Benett Ridell. Cónsul de Estados Unidos en Chihuahua. 44-14-79

1851. David R. Diffeduffer. Cónsul de Es- 
tados Unidos en Paso del Norte, Chihuahua.

$$
\text { 44-2-81 }
$$

1857. George L. Macmanus. Cónsul de Estados Unidos en Chihuahua. 44-22-64

1862. J. W. Massey. Cónsul de Estados Unidos en Chihuahua. 44.22.77

1867. Charles Moye. Vicecónsul de Estados Unidos en Chihuahua. 44-17-7

1871. Edwin Lyon. Cónsul de Estados Unidos en Paso del Norte. 444-20-120

1872. William M. Pierson. Vicecónsul de Estados Unidos en Paso del Norte. 44-22-6

1873. Ephraim Browne. Cónsul de Estados Unidos en Paso del Norte. 44-20-45

1875. W. H. Brown. Cónsul de Estados Unidos en Chihuahua. LE-1101

1875. William P. Pierson. Vicecónsul de Estados Unidos en Paso del Norte. 6-19-2

1875. John C. Huston. Vicecónsul de Estados Unidos en Chihuahua. 6-19-2-43

1875. John C. Huston. Vicecónsul de Estados Unidos en Chihuahua. 6-16-45

1876. Joseph Kanotts. Cónsul de Estados Unidos en Chihuahua. 44-20-102

1877. Luis H. Scott. Cónsul de Estados Unidos en Chihuahua. 44-17-48

1877. Salomón Schultz. Cónsul de Estados Unidos en Paso del Norte. 44-17-46

1880. Charles C. Richardson. Cónsul de Estados Unidos en Paso del Norte. 44-17-32

1883. Charles C. Richardson. Cónsul de Estados Unidos en Paso del Norte. IV $/ 032.3 " 883^{\prime \prime} / 1$
1883. William M. Pierson, Vicecónsul de Estados Unidos en Paso del Norte. IV $/ 032.3$ " 883 " 1

1883. Louis H. Scott. Cónsul de Estados Unidos en Chihuahua. 30-29-49

1883. John C. Huston. Vicecónsul de Estados Unidos en Chihuahua. 30-29-49

1884. Eugene O. Pechet. Cónsul de Estados Unidos en Paso del Norte. 42.9.49

1884. Barker Burnell. Vicecónsul de Estados Unidos en Paso del Norte. 42-9-49

1885. J. Harvey Breigham. Cónsul de Estados Unidos en Paso del Norte. 42-9-51

1885. Louis H. Scott. Cónsul de Estados Unidos en Chihuahua. 30-29-50

1885. John C. Huston. Vicecónsul de Estados Unidos en Chihuahua. 30-29-50

1885. Eugene O. Pechet. Cónsul de Estados Unidos en Paso del Norte. 30.29.50

1885. Barker Burnell. Vicecónsul de Estados Unidos en Paso del Norte. 30-29-50

1887. Remoción del cónsul americano en el Paso del Norte. 12-2-22

1887. William Heimke. Vicecónsul de Estados Unidos en Chihuahua. 42-8-3

1888. Beckford Mackey. Cónsul de Estados Unidos en Paso del Norte. 42-9.52

1888. Archibald Sampson. Cónsul de Estados Unidos en Paso del Norte. 42-9.54

1890. William B. Macluchlen. Viceauxiliar del cónsul de Estados Unidos en Paso del Norte.

$$
\text { 42.9.55 }
$$

1892. Ruwland Anderson. Vicecónsul de Estados Unidos en Chihuahua. 
47.8.5

1893. Theodore Huston. Cónsul de Estados Unidos en Paso del Norte. 42-9-56

1893. Frank A. Johnston. Cónsul de Estados Unidos en Chihuahua. 42-8-34

1894. Richard M. Burke. Cónsul de Estados Unidos en Chihuahua. 42-8-33

1895. Louis M. Buford. Cónsul de Estados Unidos en Paso del Norte. 42-17-101

1895. James J. Long. Agente consular de Estados Unidos en Parral. 42-9.57

1897. Mills William Wallace. Cónsul de Estados Unidos en Chihuahua. 42-17-132

1897. Charles W. Kindrick. Cónsul de Estados Unidos en Ciudad Juárez. 42.7.29

1898. Charles Lee Curtis. Vicecónsul de Estados Unidos en Chihuahua. 42-18-23

1899. Charles E. Wesche. Vicecónsul de Estados Unidos en Ciudad Juárez. 42-18-19

1900. Morris Heihemann. Vicecónsul de Estados Unidos en Chihuahua. 42-18-22

1901. William P. Lampe. Vicecónsul de Estados Unidos en Chihuahua. 42-8-32

1902. Charles M. Leonard. Vicecónsul de Estados Unidos en Chihuahua. 42-8-31

1904. Langhorne Marshall. Vicecónsul de Estados Unidos en Ciudad Juá. rez. 42-7-28

1905. Thomas D. Edwards. Cónsul de Estados Unidos en Ciudad Juárez. 42.7.25

1905. Edward W. Mead. Vicecónsul de Estados Unidos en Ciudad Juárez. 42.7.26

1905 Carlos E. Wesche. Vicecónsul de
Estados Unidos en Ciudad Juárez. 42.7.24

1907. John W. Courley. Vicecónsul de Estados Unidos en Ciudad Juárez. 42-8-79

1907. Luther T. Ellsnorth. Cónsul de Estados Unidos en Chihuahua. 42-8-29

1907. Lewis A. Martin. Cónsul de Estados Unidos en Chihuahua. 42-8-30

1909. LeoJ. Keena. Cónsul de Estados Unidos en Chihuahua. 42-7.195

1910. Guillermo Zoeler. Vicecónsul de Estados Unidos en Ciudad Juárez. 42-8-88

1911. Marion Letcher. Cónsul de Estados Unidos en Chihuahua. 42-8-28

1912. Edward A. Powers. Vicecónsul de Estados Unidos en Chihuahua. 42-8-27

1922. W. M. Parker Mitchell. Cónsul de Estados Unidos en Chihuahua. 42-18-171

1922. Edward A. Dow. Cónsul de Estados Unidos en Ciudad Juárez. 42.26-27

1922. José M. Asencio. Vicecónsul de Estados Unidos en Chihuahua. 42-26-68

1922. Thomas Dighton. Vicecónsul de Estados Unidos en Chihuahua. 42-26-121

1922. Finley Thomas Robinson. Vicecónsul de Estados Unidos en Ciudad Juárez. 42-26-67

1922. Walter V. Sterling. Vicecónsul de Estados Unidos en Chihuahua. 42-26-62

1926. Ollis B. Ferguson. Vicecónsul de Estados Unidos en Ciudad Juárez. 24-24-39

1927. Thomas Macenelly. Cónsul de Estados Unidos en Ciudad Juárez. 42-28-91 
1928. Robert M. Ott. Vicecónsul de Estados Unidos en Chihuahua.

$$
\text { 22-2.33 }
$$

1930. Juan Ward. Cónsul de Estados Unidos en Chihuahua. 44-17-108

1930. William B. Douglas. Vicecónsul de Estados Unidos en Ciudad Juárez. 24-24-41

1930. Louis B. Mazzeo. Vicecónsul de Estados Unidos en Chihuahua. 24-24-42

1931. Everett F. Drumight. Vicecónsul de Estados Unidos en Ciudad Juárez.

$$
\text { 24-24-62 }
$$

1932. William P. Plocker. Cónsul de Estados Unidos en Ciudad Juárez.

$$
\text { 24-25-217 }
$$

1932. Frederick E. Farnsworth. Vicecónsul comisionado en el consulado de Estados Unidos en Ciudad Juárez.

$$
\text { 22-2-36 }
$$

1942. Consulta de la Confederación Na. cional Ganadera (regional Chihuahua) sobre si es debida o no la intromisión del cónsul americano en Ciudad Juárez, al solicitar varios informes relacionados con contribuciones, prácticas agrarias, etcétera. III-628-20

2.10.2 Asuntos administrativos.

1917. Relación de los consulados enviada por el cónsul de Estados Unidos en Ciudad Juárez, Chihuahua. 27.22-91

\subsubsection{Protección.}

1877. Informes del cónsul Scott al Departamento de Estado en Washington, D. C., sobre el trato opresivo que dice reciben los americanos en Chihuahua.

$$
\text { 15-1-9 }
$$

1879. Consulado americano en Chihua- hua. Su violación por fuerzas del gobierno federal.

12-17-8

1916. Queja del representante americano que pide protección para sus compatriotas [Chihuahua].

16-19-98

1918. En Álamo, Chihuahua el representante americano pide protección para el rancho de $O$ jitos. 16-22-20

1919. Pide el representante de Estados Unidos en Casas Grandes protección para las colonias mormonas. 16-28-80

2.10.4 Actividades comerciales y culturales.

1894. El cónsul de Estados Unidos en Ciudad Juárez solicita se reforme el arancel en lo relativo a cierta clase de ganado.

$$
\text { 15-6-90 }
$$

2.10.5 Noticias, reseñas e informes.

1877. Informes del cónsul Scott al Departamento de Estado en Washington, D. C., sobre el trato opresivo que dicen reciben los americanos en Chihuahua.

$$
\text { 15.1.9 }
$$

2.11 Embajada de Estados Unidos en México.

2.11.1 Actividades diplomáticas.

2.11.1.1 Asuntos políticos.

1877. Indice de los memoranda de las conferencias celebradas entre el secretario de Relaciones [Exteriores] de México y el ministro de Estados Unidos de América [en relación con el] paso recíproco de tropas (Conferencias VallartaFoster). 40-16-143

2.11.1.2 Franquicias.

1913. La embajada americana solicita la 
libre introducción de artículos para el cónsul americano en Chihuahua. 11-4-105

2.11.1.3 Reclamaciones.

1933. A. F. Kensinger. Queja de la embajada americana por falta de canje por bonos mexicanos de un certificado a favor de la Chihuahua Investment Co.

III-129-27

2.11.2 Asuntos políticos. Noticias, reseñas $\mathrm{e}$ informes.

1912. Informes de la embajada americana relativos a Ciudad Juárez, en poder de fuerzas rebeldes.

\section{7·10-229}

2.11.3 Actividades consulares. Protección.

1895. Recomendación del encargado de negocios de Estados Unidos en favor del reo E. W. Cogdon, preso en Chihuahua. ff. 109-140.

17.21.93

1911. La embajada de Estados Unidos pide protección para las minas: Minas Prietas, Creston Comanche Co. y la Duramill Co., en Sonora; Dolores Mines Co. y El Rayo Mines Co. en Chihuahua.

$$
\text { 16-4.96 }
$$

1918. Pide la embajada norteamericana se averigüe el paradero de Tom Kingabury, administrador de la Palomas Land and Cattle Company. 16-23-53

1918. La embajada de Estados Unidos pide protección para las compañías mineras en Chihuahua.

16-29-137

1919. La Batopilas Mining Co., por conducto de la embajada de Estados Unidos, se queja de haber sufrido perjuicios y pide protección.

$$
16-27.47
$$

1958. Solicitud de la embajada de Estados Unidos en México, para que se le proporcione copia de las resoluciones dictadas por la Suprema Corte de Justicia en Chihuahua. III-2255

\subsection{Cancillería de Estados Unidos.}

\subsubsection{Actividades diplomáticas.}

2.12.1.1 Correspondencia.

1883. Correspondencia entre la legación de México en Estados Unidos y el Departamento de Estado de Estados Unidos, relativa a depredaciones de los indios apaches y chiricachuas en Sonora y Chihuahua.

$35 \cdot 15 \cdot 34$

\subsubsection{Reclamaciones.}

1859. Estados Unidos protesta contra el decreto de 15 de octubre de 1858 [emitido por] la Legislatura del estado [Chihuahua].

$$
\text { 2-4-2407 }
$$

1888. Obras de defensa del lado mexicano en el río Bravo, frente a El Paso, Texas. Conferencia entre los representarites de ambos países con motivo [de] la reclamación de las autoridades de El Paso, Texas.

$$
\mathrm{x}-3.9
$$

1888-90 Diques en la orilla mexicana del río Bravo, frente a El Paso, Texas. Gestiones del gobierno americano para que se [dejen de construir a causa de la] queja del ayuntamiento 1888-96 de El Paso, Texas (3 partes).

1898-1907

$\mathrm{x}-41$

2.12.1.3 Negociaciones.

1877. Índice de los memoranda de las conferencias entre el secretario de Relaciones [Exteriores] de México y el ministro de Estados Unidos [en relación con el] paso recíproco de tropas (Conferencias Vallarta-Foster). 40-16-143 
2.12.1.2 Asuntos militares. Noticias, reseñas e informes.

1918. Informe del secretario de Estado de Estados Unidos, mister Polk, relativos a movimientos de Francisco Villa. $17-16-175$

\subsubsection{Actividades consulares. Pro- tección.}

1919. El gobierno americano solicita permiso para que vaya a Chihuahua una flotilla aérea a recoger a sus nacionales.

17-15-149

3. Chihuahua/México y sus relaciones con Bolivia. Consulados de Bolivia en Chihuahua. Actividades consulares. Representantes.

1902. Federico Terrazas. Cónsul de Bolivia en Chihuahua. 42-6-20

1906. José Asúnsolo. Cónsul de Bolivia en Chihuahua. 42-6-22

4. Chihuahua/México y sus relaciones con Canadá. Actividades consulares. Migración.

1922. Colonización de Chihuahua por menonitas procedentes de Canadá. 27-4-71

5. Chihuahua/México y sus relaciones con Colombia. Legación de México en Co. lombia. Asuntos administrativos.

1929. Acuse de recibo de información de la legación de México en Bogotá, Colombia a la SRE, sobre la apertura de las aduanas de Ciudad Juárez, Chihuahua.

IV-28-4
6. Chihuahua/México y sus relaciones con Costa Rica. Consulados de Costa Rica en Chihuahua. Actividades consulares. Representantes.

1925. Claudio Loria Montenegro. Cónsul de Costa Rica en Parral. 42-20-19

7. Chihuahua/México y sus relaciones con Alemania.

7.1 Actividades consulares. Protección.

1919. Alemanes se quejan de que el gobierno de Chihuahua ordenó su incorporación a las defensas sociales. 16-28-121

7.2 Legación de Alemania en México. Actividades consulares. Protección.

1912. Gestión de la legación alemana para obtener protección del tráfico [del] Ferrocarril Central en Ciudad Juárez. 12-9-74

7.3 Consulados de Alemania en Chihuahua. Actividades consulares. Representantes.

1883. Wilhem Vermehren. Vicecónsul de Alemania en Chihuahua. 30.29.49

1885. Guillermo Kehder. Encargado del viceconsulado de Alemania en Chihuahua. 42-6-156

1885. Wilhem Vermehren. Vicecónsul de Alemania en Chihuahua. 30-29-49

1885. Emile Ketelsen. Vicecónsul de Ale. mania en Chihuahua. 42-6-155

1887. Otto Sartorius. Encargado del viceconsulado de Alemania en Chihuahua.

$$
\text { 42-6-154 }
$$


1888. Francisco Reimers. Encargado del viceconsulado de Alemania en Chihuahua. 42.6-160

1893. Emile Ketelsen. Vicecónsul de Alemania en Chihuahua. 42-6-155

1893. Otto Sartorius. Encargado del viceconsulado de Alemania en Chihuahua.

$$
\text { 42-16-155 }
$$

1893. Max Weber. Vicecónsul de Alemania en Ciudad Juárez. 42-6.152

1897. Alfredo Plessing. Encargado del viceconsulado de Alemania en Ciudad Juárez. 42-6-151

1899. Ausuto Seekamp. Encargado del viceconsulado de Alemania en Ciu. dad Juárez. 42-6-150

1907. Otto Kuck. Vicecónsul de Alemania en Chihuahua.

$$
\text { 42-6-159 }
$$

1912. Dificultades del gobierno de Chihuahua con el cónsul alemán en lla localidad]. $16 \cdot 7 \cdot 128$

1912. Alberto Stallforth. Agente consular de Alemania en Parral. 42-6.115

1913. El cónsul Otto Kuck [alemán] comunica sus dificultades con el gobierno de Chihuahua. $16-7-128$

1917. Ernest H. Coldnder. Cónsul de Alemania en Chihuahua. 42-20-1

1917. Gustavo Heuser. Vicecónsul de Alemania en Ciudad Juárez. 6-13-53

1922. Federico Reuter. Vicecónsul de Alemania en Ciudad Juárez. 42-18-92

1822. Guillermo Vermehren. Vicecónsul de Alemania en Chihuahua. 42-6-157
1926. Johannes Spann. Cónsul honorario de Alemania en Chihuahua. 19-18-3

1934. Adalbert Weppen. Cónsul honorario de Alemania en Chihuahua. 24.25.227

8. Chihuahua/México y sus relaciones con España.

8.1 Actividades diplomáticas. Asilo político.

1950. Informes de prensa relativos a que se descubrió una estación radiodifusora clandestina en Chihuahua, que operaba bajo las órdenes del refugiado español Enrique $R i$ card.

III.2076-16

8.2 Actividades consulares. Protección.

1913. Españoles en Chihuahua, su protección.

$$
\text { 12-11-110 }
$$

8.3 Consulados de España en Chihuahua. Actividades consulares.

8.3.1 Representantes.

1826. Anselmo Pereda. Vicecónsul de España en Chihuahua.

$$
\text { 2-3-2138 }
$$

1845. Juan Mande. Vicecónsul de España en Chihuahua.

$$
\text { 2-3-2138 }
$$

1845. José María de Uria Nafarrondo. Vicecónsul de España en Chihuahua.

$$
\text { 44-20-4 }
$$

1851. Anselmo Pereda. Vicecónsul de España en Chihuahua.

$$
\text { 44-22-109 }
$$

1905. Francisco de Asís Caballero y Mediano. Cónsul en Chihuahua.

$$
\text { 42.7.106 }
$$

1922. Secundino F. Hevia. Agente consu- 
lar de España en Parral.

24-24-16

8.3.2 Migración.

1931. El consulado de España en Hidalgo del Parral solicita informes sobre permisos de emigración. IV-393-40

8.3.3 Noticias, reseñas e informes.

1929. El consulado de México en Presidio, Texas informa a la SRE sobre el fraude cometido por el ciudadano español Fidencio Calvo, en perjuicio de comerciantes mexicanos en Chihuahua. IV.76-28

9. Chihuahua/México y sus relaciones con Francia.

9.1 Actividades consulares. Protec. ción.

1911. Franceses en Guadalupe y Calvo, Parral. Su protección. 16-5-105

9.2 Consulados de Francia en Chihuahua. Actividades consulares. Representantes.

1826. Pedro Delille. Vicecónsul de Francia en Chihuahua.

$$
\text { 2-3-2138 }
$$

1852. Roger Duboc. Vicecónsul de Francia en Chihuahua. 44-17-166

1860. Pedro Delille. Vicecónsul de Fran. cia en Chihuahua. 44-9-11

1916. Jean Ramonfaur. Agente consular honorario de Francia en Chihuahua. 24-24-11

10. Chihuahua/México y sus relaciones con Gran Bretaña.

10.1 Actividades consulares. Protección.

1911. Ingleses en Guadalupe y Calvo. Su protección.

16.5.105

10.2 Consulados de Gran Bretaña en México. Actividades consulares. Protección. 16-19-102

1916. Dice el vicecónsul británico en el distrito de Chihuahua que abriga temores respecto al peligro que corren [sus nacionales].

16:19-102

11. Chihuahua/México y sus relaciones con Italia. Consulados de Italia en Chihuahua. Actividades consulares. Representantes.

1909. Giuseppe Attolini. Agente consular de Italia en Chihuahua.

31-7-x

1911. Otto Gluck. Agente consular de Italia en Chihuahua. 31-7-x

1916. Giuseppe de Estefoso. Agente consular honorario de Italia en Chihuahua. 24.25.234

1927. Giuseppe de Stefano. Agente consular de Italia en Chihuahua.

$31 \cdot 7 \cdot x$

12. Chihuahua/México y sus relaciones con Suiza. Consulados de Suiza en Chihuahua. Actividades diplomáticas. Reclamaciones.

1943. Queja del consulado de Suiza en México contra la Compañía Cervecera de Chihuahua por uso indebido del escudo suizo. III-649.18

13. Chihuahua/México y sus relaciones con la URSS. Embajada de la URSS en México. Actividades consulares. Protección. 
1943. Queja del embajador de la Unión de Repúblicas Socialistas Soviéticas en contra de autoridades mexicanas de emigración en Ciudad Juárez, por atropellos cometidos en contra del señor Yuri Vdovin y otro [señor]. III-655-11

14. Chihuahua/México y sus relaciones con China.

\subsection{Actividades consulares.}

14.1.1 Migración.

1930. Inmigración china por Ciudad Juárez, Chihuahua. IV-396-44

\subsubsection{Protección.}

1912. Chinos en Chihuahua. Su protección.

$$
\text { 13-2-50 }
$$

1916. Supuesto asesinato de chinos en Chihuahua.

$$
\text { 13-2-97 }
$$

1919. Chinos se quejan de que sufrieron un saqueo en Pearson, Chihuahua. 16.30-49

1932. En representación de la colonia china de Hidalgo del Parral, se queja contra el presidente municipal por el cobro de derecho por la visa de sus tarjetas de registro. IV.181-32

14.2 Legación de China en México. Actividades consulares.

\subsubsection{Protección.}

1915. El ministro de China pide protección para los chinos en Baja California y Chihuahua. 16-4.54
1916. La legación de China pide garantías para los chinos en Ciudad Juárez. 16-12-171

15. Chihúahua/México y sus relaciones con Japón.

15.1 Actividades consulares. Migración.

1914. Japoneses [en] Chihuahua. L-E-794 (11)

15.2 Consulados de México en Japón. Actividades consulares. Migración.

1930. Consulta del delegado de Migración en Ciudad Juárez sobre visa a los pasaportes de chinos [expedida] por el consulado de México en Yokohama, Japón.

IV-396-40

\section{BIBLIOGR AFÍA}

-Katz, Friedrich, La guerra secreta en México, 2 vols. Ediciones Era, México, 1982 (El hombre y su tiempo). , "Pancho Villa, los movimientos campesinos y la reforma agraria en el norte de México", en David A. Brading (comp.), Caudillos y campesinos en la revolución mexicana, Fondo de Cultura Económica, México, 1985.

-Krauze, Enrique, Por una democracia sin adjetivos, Joaquín Mortiz-Planeta, México, 1986.

, Entre el ángel y el fierro. Francisco Villa, Fondo de Cultura Económica, México, 1988 (Biografias del Poder, 4). 